REVIEW ARTICLE

\title{
Production of high-energy Li-ion batteries comprising silicon-containing anodes and insertion-type cathodes
}

\author{
Gebrekidan Gebresilassie Eshetu1,2,10, Heng Zhang ${ }^{3,10}$, Xabier Judez ${ }^{4}$, \\ Henry Adenusi ${ }^{5,6,7,8}$, Michel Armand (10 ${ }^{4}$, Stefano Passerini (i) ${ }^{5,6,8 凶}$ \& \\ Egbert Figgemeier $1,9 凶$
}

Rechargeable Li-based battery technologies utilising silicon, silicon-based, and Si-derivative anodes coupled with high-capacity/high-voltage insertion-type cathodes have reaped significant interest from both academic and industrial sectors. This stems from their practically achievable energy density, offering a new avenue towards the mass-market adoption of electric vehicles and renewable energy sources. Nevertheless, such high-energy systems are limited by their complex chemistry and intrinsic drawbacks. From this perspective, we present the progress, current status, prevailing challenges and mitigating strategies of Li-based battery systems comprising silicon-containing anodes and insertion-type cathodes. This is accompanied by an assessment of their potential to meet the targets for evolving volumeand weight-sensitive applications such as electro-mobility.

ncentivised by the ever-increasing markets for electro-mobility and the efficient deployment of renewable energy sources, there is a large demand for high-energy electrochemical energy storage devices ${ }^{1-7}$. Lithium-ion batteries (LIBs) utilising graphite $(\mathrm{Gr})$ as the anode and lithium cobalt oxide $\left(\mathrm{LiCoO}_{2}, \mathrm{LCO}\right)$ as the cathode have subjugated the battery market since their commercialisation by Sony in the $1990 \mathrm{~s}^{8,9}$. They are responsible for $63 \%$ of worldwide battery sales with an estimated global market value of US $\$ 213.5$ billion by $2020^{10}$. Within this share, the automotive end-use industry is predicted to lead the overall mass market due to an increasing interest in EVs (http://www.ev-volumes.com/) ${ }^{11}$.

However, despite the striking growth in sales of LIBs worldwide, the practical specific energy of contemporary commercial LIBs $\left(\sim 250 \mathrm{Wh} \mathrm{kg}^{-1}\right.$ based on a $\mathrm{Gr} \mid$ lithium nickel manganese cobalt oxide (NMC) cell) is not adequate to achieve the stringent requirements of nextgeneration batteries ${ }^{6}$. This implies that to stimulate EV market penetration, improvements, mainly including specific energy and energy density $\left(>400 \mathrm{Wh} \mathrm{kg}^{-1}\right.$ and $\left.>800 \mathrm{Wh} \mathrm{L}-1\right)$ to

\footnotetext{
${ }^{1}$ Institute of Power Electronics and Electric Drives, ISEA, RWTH Aachen, Aachen, Germany. ${ }^{2}$ Department of Material Science and Engineering, Mekelle Institute of Technology-Mekelle University, Tigray, Ethiopia. ${ }^{3}$ Key Laboratory of Material Chemistry for Energy Conversion and Storage (Ministry of Education), School of Chemistry and Chemical Engineering, Huazhong University of Science and Technology, Wuhan, China. ${ }^{4}$ Centre for Cooperative Research on Alternative Energies (CIC energiGUNE), Basque Research and Technology Alliance (BRTA), Vitoria-Gasteiz, Spain. ${ }^{5}$ Karlsruhe Institute of Technology (KIT), Karlsruhe, Germany. ${ }^{6}$ Helmholtz Institute Ulm (HIU), Ulm, Germany. ${ }^{7}$ Hong Kong Quantum AI Lab (HKQAI), New Territories, Hong Kong, China. ${ }^{8}$ Department of Chemistry University of Rome "La Sapienza", Rome, Italy. ${ }^{9}$ Helmholtz Institute Münster (HI MS), IEK-12, Forschungszentrum Jülich, Münster, Germany. ${ }^{10}$ These authors contributed equally: Gebrekidan Gebresilassie Eshetu, Heng Zhang. ${ }_{\text {email: stefano.passerini@kit.edu; }}$ e.figgemeier@fz-juelich.de
} 
enable long-range driving $(>500 \mathrm{~km}$ ), rate capability (i.e. high current density, $\geq 2 \mathrm{C}$, the symbol ' $\mathrm{C}$ ' represents the current rate used for cycling rechargeable batteries, $x \mathrm{C}$ refers to the current required to fully charge/discharge the battery in $1 / x \mathrm{~h}$ ), and cost

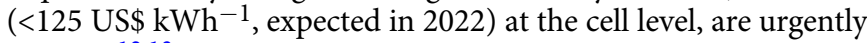
required $^{12,13}$.

Transitioning beyond the horizon of prevailing LIBs to avoid 'driving range anxiety' and thereby contending with traditional combustion engine vehicles in terms of driving range per charge demands the exploration of novel chemistries and materials. Since the energy density of batteries is determined by Coulombic capacity and cell voltage, the combination of a wide redoxpotential gap and high-capacity electrode materials is of fundamental importance. Rechargeable lithium metal $\left(\mathrm{Li}^{0}\right)$-based batteries (LMBs) have emerged as promising technologies, yet their large-scale deployment has never been feasible except for Li-metal polymer batteries commercialised on a relatively small scale by Bollore (https://www.blue-solutions.com/en/). This is due to the thermodynamic and kinetic instability of the $\mathrm{Li}^{\%} /$ electrolyte interphase induced by dendrite/mossy formation during the plating/stripping processes.

To bypass the challenges associated with $\mathrm{Li}^{0}$ anodes, various research and development $(\mathrm{R} \& \mathrm{D})$ ventures have led to several (high capacity) alternative strategies to replace dendritic $\mathrm{Li}^{0}$ deposits while maintaining similar operating voltages and safer electrode materials ${ }^{5-7}$. Accordingly, as illustrated in Fig. 1, silicon $(\mathrm{Si})$, silicon-based (Si-B, e.g. silicon-graphite ( $\mathrm{Si} / \mathrm{Gr})$ ), and silicon derivatives ( $\mathrm{Si}-\mathrm{D}$, e.g. silicon oxide $\left(\mathrm{SiO}_{x}\right)$, silicon oxide-graphite $\left(\mathrm{SiO}_{x} / \mathrm{Gr}\right)$, silicon nitride $\left(\mathrm{SiN}_{x}\right)$, etc.) have been developed as one of the most propitious anode materials due to their various benefits in comparison to other commercial anode materials (Supporting Table 1) ${ }^{14}$. On the other hand, to achieve LIBs with high-energy, high-capacity/high-voltage positive electrodes are a prerequisite. Insertion cathodes (ICs), especially Ni-rich NMC, $\mathrm{Ni}, \mathrm{Co}$ and $\mathrm{Al}$ (dubbed NCA), Li-rich NMC and high-voltage materials, are among the most appealing materials, considering their straightforward chemistries ${ }^{15}$. Thus, rechargeable batteries built by pairing high-capacity, low-potential $\mathrm{Si}$ and/or $\mathrm{Si}-\mathrm{B} / \mathrm{Si}-\mathrm{D}$ anodes with IC materials have been highly investigated to enable next-generation LIBs. This is evidenced by the increasing number of research works published in the last 5 years (Fig. 1).

From this perspective, we present an in-depth analysis of rechargeable batteries built from $\mathrm{Si} / \mathrm{Si}-\mathrm{B} / \mathrm{Si}-\mathrm{D}$ anodes coupled with IC cathode materials. In an attempt to avoid simply narrating, 'who did what, and when?', the available literature has been critically inspected, and prospects for development opportunities, insight into future research directions and guidelines for the advancement of $\mathrm{Si} / \mathrm{Si}-\mathrm{B} / \mathrm{Si}-\mathrm{D}|| \mathrm{IC}$ cells are also given. Furthermore, a detailed analysis of materials chemistry with a focus on evaluating key metrics such as electrochemical performance, economic viability, safety, and reliability is provided.

\section{Cell chemistry}

Negative electrode chemistry: from pure silicon to siliconbased and silicon-derivative

Pure Si. The electrochemical reaction between $\mathrm{Li}^{0}$ and elemental Si has been known since approximately the 1970s; in particular, $\mathrm{Li}-\mathrm{Si}$ alloys $\left(\mathrm{Li}_{x} \mathrm{Si}, 0<x \leq 4.4\right)$ were of great curiosity for use as anodes in elevated-temperature molten salt electrolyte batteries operating in the $350-500{ }^{\circ} \mathrm{C}$ range ${ }^{16}$. The $\mathrm{Li}-\mathrm{Si}$ alloy reaction plays a critical role in utilising $\mathrm{Si}$ as an anode material. Based on the equilibrium of the $\mathrm{Li}-\mathrm{Si}$ binary phase diagram, various intermetallic states are favourably formed at distinct thermodynamic voltage plateaus and temperatures (Fig. 2A). The reaction potential decreases with an increasing degree of lithiation (insertion of $\mathrm{Li}$ into the active host material). By virtue of its overwhelming attributes, $\mathrm{Si}$ has attracted increased attention from the academic and industrial research communities along with policymakers as a next-generation anode material ${ }^{11}$. Nevertheless, the practical application of pure Si- and/or high Si-containing anodes is currently impeded by the presence of multiple interrelated challenges: the enormous volume change $(>280 \%)$ of $\mathrm{Si}$ upon full lithiation induces severe cracking and pulverisation of anodes (at both the active material and electrode levels), a much lower electronic conductivity $\left(\sigma_{\mathrm{e}}<10^{-5} \mathrm{~S} \mathrm{~cm}^{-1}\right)$ and $\mathrm{Li}^{+}$diffusion rate $\left(D_{\mathrm{Li}}^{+}, 10^{-14}-10^{-13} \mathrm{~cm}^{2} \mathrm{~s}^{-1}\right)$ in high-purity $\mathrm{Si}$ compared to that of carbon and graphite $\left(\sigma_{\mathrm{e}-}, 10-10^{4} \mathrm{~S} \mathrm{~cm}^{-1} ; D_{\mathrm{Li}}{ }^{+}\right.$,

A
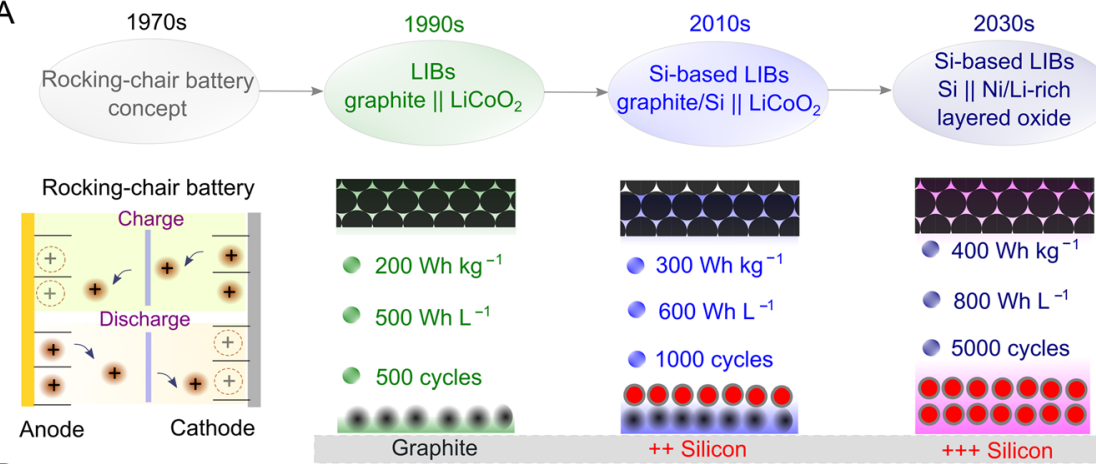

B

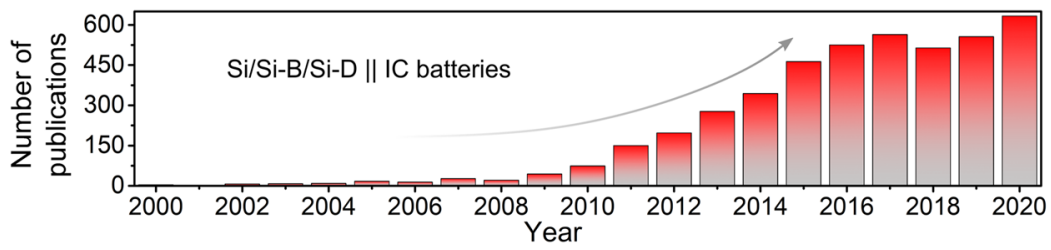

Fig. 1 Overview of the development of LIBs over the years. A Evolution of LIBs from the rocking-chair battery concept to today's LIBs and next-generation $\mathrm{Si} / \mathrm{Si}-\mathrm{B} / \mathrm{Si}-\mathrm{D}|| \mathrm{IC}$ batteries. Key indicators (specific energy, energy density and cycle life) are comparatively displayed. B Research trend in the field of Si/SiB/Si-D IIC cells. (Last updated on June 28th, 2021 at 2 pm, Berlin time). The key search words used in Scopus ${ }^{\circledR}$ were 'lithium-ion battery + silicon anode/ Si-based/derivatives + insertion and/or intercalation cathode'. 


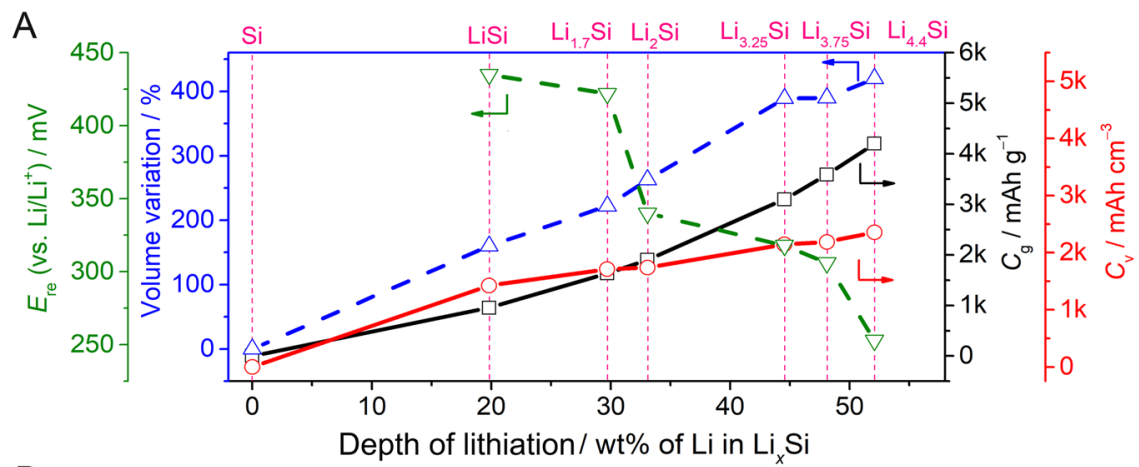

B

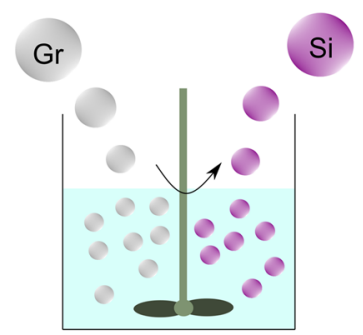

Blending Si with $\mathrm{Gr}$
C

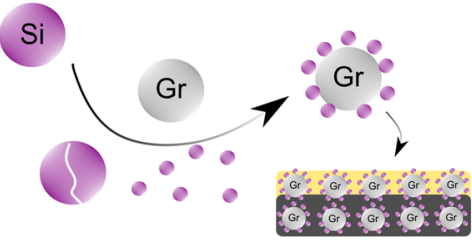

Single Si/Gr composite electrode

$\mathrm{D}$

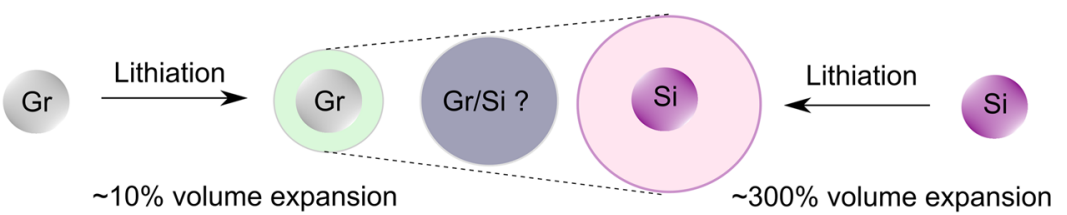

Fig. 2 Negative electrode chemistry for pure silicon and Si-based materials. A Theoretical capacity $\left[\right.$ specific $\left(C_{g}\right)$ and volumetric capacity $\left.\left(C_{v}\right)\right]$, volume variation upon (de)alloying, and reaction potential $\left(E_{\mathrm{re}}\right)$ for various lithiated Si electrodes. B Mechanical blending of Si with $\mathrm{Gr}$ during the electrode fabrication process. C Building a single Si/Gr composite electrode. D Volume expansion in Si-Gr blend/composite electrodes.

$\left.10^{-9} \mathrm{~cm}^{2} \mathrm{~s}^{-1}\right)^{17-19}$, unstable/dynamic solid electrolyte interphase (SEI) formation, electrode swelling and electrolyte drying ${ }^{14}$.

Si-based materials: Si-graphite blend/composite, Si-containing functional second phase. To mitigate the challenges linked to pure $\mathrm{Si}$, coupling $\mathrm{Si}$ and $\mathrm{Gr}$ has been hailed as the most effective strategy towards the commercialisation of Si anode-based highenergy LIBs ${ }^{17-19}$. Adding $\mathrm{Gr}$ to Si materials buffers the volume change of the overall composite electrode (not individual $\mathrm{Si}$ particles) at a relatively low $\mathrm{Si}$ content $(\sim 20 \% \mathrm{Si})$ because the major portion of the reactive sites for SEI formation is provided by the graphite particles ${ }^{20}$. The addition of $\mathrm{Gr}$ to $\mathrm{Si}$ also increases the diffusivity $\left(\delta_{\mathrm{e}-}\right.$ and $\left.D_{\mathrm{Li}}{ }^{+}\right)$of the electrode and improves its processability in terms of electrode manufacturing (e.g. calendaring), thus enabling high specific, areal and volumetric capacities. Co-utilisation can be achieved by blending $\mathrm{Si}$ with $\mathrm{Gr}$ during the electrode fabrication process (Fig. $2 \mathrm{~B}$ ) or by building a single Si-Gr composite electrode (Fig. 2C). Moreover, the coutilisation of $\mathrm{Si}$ and $\mathrm{Gr}$ can be considered as drop-in technology of graphite, i.e. adopting existing scalable synthesis protocols, establishing commercial production lines, translating into high manufacturability and providing a marginal investment of present graphite-based LIB technology. This accelerates the largescale deployment of $\mathrm{Si}-\mathrm{Gr}$ anodes without disrupting established manufacturing lines ${ }^{21}$. To date, battery manufacturers have introduced small amounts of $\mathrm{Si}(<6-8 \mathrm{wt} . \%)$, yet incorporating up to $50-60 \mathrm{wt} . \%$ Si remains a serious obstacle due to large volume change-induced SEI failure, accelerated electrolyte decomposition and drying out ${ }^{14}$. The use of a high Si content can only be realised by the synergistic optimisation of various parameters, including polymeric binders compatible with $\mathrm{Gr}$ and $\mathrm{Si}$ chemistries, functional additives, pre-lithiation, surface functionalisation, protective coatings, etc ${ }^{20}$. The individual materials (i.e. $\mathrm{Gr}, \mathrm{Si}$ ) and their physical blend/composites possess different characteristics and failure mechanisms (e.g. different rates for volume expansion, as shown in Fig. 2D), calling for different diagnostic approaches. Moreover, the difference in the (de)lithiation potentials of $\mathrm{Gr}$ and $\mathrm{Si}$ (e.g. $\sim 20 \mathrm{mV}\left(\mathrm{LiC}_{6}\right)$ vs. $250 \mathrm{mV}\left(\mathrm{Li}_{4.4} \mathrm{Si}\right)$ vs. $\mathrm{Li} / \mathrm{Li}^{+}$, Fig. $2 \mathrm{~A}$ ) incurs further complexity towards understanding the actual working mechanism of the blended and/or composite electrode systems.

In addition to adding $\mathrm{Gr}$ to $\mathrm{Si}$, Si-containing functional second phases, including embedding $\mathrm{Si}$ particles into a continuous carbon matrix such as graphene, carbon nanotubes (CNTs), and carbon nanofibres (CNFs), as well as designing Si-containing encapsulated structures, including core-shell, yolk-shell and tailored porous structures, are among the most investigated anode materials at the laboratory scale; however, transfer to the industrial level remains challenging ${ }^{22}$.

Silicon-derivative materials: $\mathrm{SiO}_{x}, \mathrm{SiO}_{x}-\mathrm{Gr}$ and $\mathrm{SiN}_{x}$ $\mathrm{SiO}_{\mathrm{x}}$. Recently, silicon oxide $\left(\mathrm{SiO}_{x}, 0<x \leq 2\right)$ has been investigated as a promising replacement for elemental Si due to its easy synthesis, mild theoretical volume expansion $(\sim 118 \%$ for $\mathrm{SiO}$ compared to $\mathrm{Si}, \geq 300 \%)$, and low $\operatorname{cost}^{23}$. The blending of $\mathrm{Si}$-rich $\mathrm{SiO}_{x}(x \leq 1)$ with $\mathrm{Gr}$ has become a hotspot leading to its commercialisation in LIBs (usually $\mathrm{SiO}_{x}<10$ wt.\% $)^{7,24}$. The $\mathrm{SiO}_{x}$ family includes silicon monoxide ( $\mathrm{SiO}$ )-, silicon dioxide $\left(\mathrm{SiO}_{2}\right)$, non-stoichiometric $\mathrm{SiO}_{x}$ and silicon oxycarbide ( $\mathrm{Si}-\mathrm{O}-\mathrm{C}$ )-based anode materials. The $\mathrm{O}$ content affects the specific capacity, cycle life and voltage hysteresis (voltage hysteresis refers to the voltage difference between the 
charge and discharge profiles) ${ }^{25}$. For instance, high $\mathrm{O}$ contents result in extended cycle life and high-voltage hysteresis due to the release in the strain and stress of the Li-ion insertion/extraction processes $^{26}$, while lowering the initial Coulombic efficiency (ICE) and rate capability. This is mostly due to the irreversible consumption of active $\mathrm{Li}^{+}$ions (e.g. forming $\mathrm{Li}_{2} \mathrm{O}$ and $\mathrm{Li}_{4} \mathrm{SiO}_{4}$ ). Although still under investigation, it is generally accepted that the first lithiation of $\mathrm{SiO}_{x}$ families, for instance, $\mathrm{SiO}$, results in the formation of $\mathrm{Li}_{x} \mathrm{Si}, \mathrm{Li}_{2} \mathrm{O}\left(\mathrm{SiO}+2 \mathrm{Li}^{+}+2 \mathrm{e}^{-} \rightarrow \mathrm{Si}+\mathrm{Li}_{2} \mathrm{O}\right)$, Li-silicates (e.g. $\mathrm{Li}_{4} \mathrm{SiO}_{4}: 4 \mathrm{SiO}+4 \mathrm{Li}^{+}+4 \mathrm{e}^{-} \rightarrow 3 \mathrm{Si}+\mathrm{Li}_{4} \mathrm{SiO}_{4}$; $\mathrm{Li}_{2} \mathrm{Si}_{2} \mathrm{O}_{5}: \quad 5 \mathrm{SiO}+2 \mathrm{Li}^{+}+2 \mathrm{e}^{-} \rightarrow 3 \mathrm{Si}+\mathrm{Li}_{2} \mathrm{Si}_{2} \mathrm{O}_{5} ; \quad \mathrm{Li}_{6} \mathrm{Si}_{2} \mathrm{O}_{7}$ : $7 \mathrm{SiO}+6 \mathrm{Li}^{+}+6 \mathrm{e}^{-} \rightarrow 5 \mathrm{Si}+\mathrm{Li}_{6} \mathrm{Si}_{2} \mathrm{O}_{7}$ ), and $\mathrm{Li}_{2} \mathrm{SiO}_{3}$ (e.g. $\left.3 \mathrm{SiO}+2 \mathrm{Li}^{+}+2 \mathrm{e}^{-} \rightarrow 2 \mathrm{Si}+\mathrm{Li}_{2} \mathrm{SiO}_{3}\right)$.

$\operatorname{SiN}_{\mathrm{x}}$. Silicon nitride $\left(\mathrm{SiN}_{x}\right)$ is another family of Si derivatives that electrochemically undergoes a two-stage reaction, i.e. a conversion reaction leading to the formation of electrochemically stable and $\mathrm{Li}$-ion conductive $\mathrm{Li}-\mathrm{Si}-\mathrm{N}$ compounds (e.g. $\mathrm{Li}_{2} \mathrm{SiN}_{2}{ }^{27}$ ), followed by an alloying reaction, resulting in $\mathrm{Si}$ nanoparticles (SiNPs) ${ }^{28-30}$. Stoichiometrically, increasing the nitrogen content in $\mathrm{SiN}_{x}$ gradually reduces the reversible capacity while increasing the cycling stability and rate capability ${ }^{29}$. The physical distribution of $\mathrm{Li}$ silicon nitride products $\left(\mathrm{Li}_{x} \mathrm{SiN}_{y}\right)$ after lithiation reactions greatly affects the cycling performance of $\mathrm{SiN}_{x}$ electrodes ${ }^{30}$. Despite the promising performances obtained in terms of cycling stability and rate capability, $\mathrm{SiN}_{x}$ anode-based Li-ion batteries are not commercially viable. To implement $\mathrm{SiN}_{x}$ in practical cells, strategies that use powder-based electrodes and improve its low first-cycle Coulombic efficiency (e.g. use of additives) need to be adopted.

Positive electrode chemistry. In contrast to Li-free electroactive materials [e.g. titanium disulfide $\left(\mathrm{TiS}_{2}\right)^{31}$, which require a highly reactive lithium-metal anode ${ }^{32}$, Goodenough and co-workers discovered several important Li-containing cathodes (e.g. $\mathrm{LiCoO}_{2}(\mathrm{LCO})^{33}$, lithium manganese oxide $\left(\mathrm{LiMn}_{2} \mathrm{O}_{4}, \mathrm{LMO}\right)^{34}$, and lithium iron phosphate $\left.\left(\mathrm{LiFePO}_{4}, \mathrm{LFP}\right)^{35}\right)$ that could not only increase the operational voltage (i.e. from 3 to $4 \mathrm{~V}$ ) of rechargeable batteries but also permit the production of batteries under less controlled conditions (e.g. a clean room with a relative humidity of $\sim 30 \%)^{9}$. In recent years, due to the drawbacks of individual layered cathode materials (e.g. LCO and LMO) and the quest to improve the energy density of LIBs, cathode materials with higher voltage and/or capacity have been proposed, including nickel-rich layered oxides ( $\mathrm{LiNi}_{1-x} \mathrm{M}_{x} \mathrm{O}_{2}, \mathrm{M}=\mathrm{Co}, \mathrm{Mn}$, and $\mathrm{Al}$ ), lithium-rich layered oxides ( $\mathrm{Li}_{1+x} \mathrm{M}_{1-x} \mathrm{O}_{2}, \mathrm{M}=\mathrm{Mn}, \mathrm{Ni}, \mathrm{Co}$, etc.), high-voltage spinel oxides ( $\left.\mathrm{LiNi}_{0.5} \mathrm{Mn}_{1.5} \mathrm{O}_{4}, \mathrm{LNMO}\right)$, and others, as reported and discussed in the literature ${ }^{36-38}$. Figure $3 \mathrm{~A}$ comparatively illustrates the discharge profiles of some of the representative cathode materials of each of the families. Considering $\mathrm{Li} / \mathrm{Li}^{+}$as a reference redox couple, the cell voltage increases on the order of $\mathrm{TiS}_{2} \quad(\sim 2.0 \mathrm{~V})<\mathrm{LFP} \quad(\sim 3.4 \mathrm{~V})<\mathrm{LCO} \approx \mathrm{LMO} \approx \mathrm{LiNi}_{1 / 3} \mathrm{Mn}_{1 / 3} \mathrm{Co}_{1 /}$ ${ }_{3} \mathrm{O}_{2} \quad(\mathrm{NMC111}) \quad(\sim 3.7 \mathrm{~V})<\mathrm{LiNi}_{0.8} \mathrm{Mn}_{0.1} \mathrm{Co}_{0.1} \mathrm{O}_{2} \quad(\mathrm{NMC} 811), \approx$ LNMO $(\sim 4.8 \mathrm{~V})$. Nevertheless, the cell capacity does not follow the same tendency, thus requiring the selection of a particular cell configuration for attaining optimal energies (see the 'Energy density estimation of full cell' section).

Ternary oxides such as NMC and NCA can provide theoretical capacities in the range of $200-210 \mathrm{mAh} \mathrm{g}^{-1}$ in the voltage window of 3.0-4.3 V vs. $\mathrm{Li} / \mathrm{Li}^{+39}$. The logic behind the mixing of $\mathrm{Ni}, \mathrm{Co}$ and $\mathrm{Mn}$ or $\mathrm{Al}$ is attributed to their crucial elemental physical properties, including the high capacity and voltage of $\mathrm{Ni}$, fast charge-discharge kinetics of $\mathrm{Co}$, structural cycling stability of $\mathrm{Mn}$ and improved thermal stability of $\mathrm{Al}^{36-38}$. Regarding NMC variants, increasing the $\mathrm{Ni}$ content from NMC111 to NMC811 and beyond provides highly encouraging features, including improved specific capacity, higher diffusivity (both $\sigma_{\mathrm{e}-}$ and $D_{\mathrm{Li}+}$ ), and decreased material use and overall cost (Fig. 3B). Due to having both higher electronic conductivity $\left(\sim 10^{-8} \mathrm{~S} \mathrm{~cm}^{-1}\right.$ for NMC111 vs. $\sim 10^{-5} \mathrm{~S} \mathrm{~cm}^{-1}$ for NMC811) and $\mathrm{Li}^{+}$diffusivity $\left(10^{-11}-10^{-12} \mathrm{~cm}^{2} \mathrm{~s}^{-1}\right.$ for NMC111 vs. $10^{-8}-10^{-9} \mathrm{~cm}^{2} \mathrm{~s}^{-1}$ for NMC811), the rate capability of NMC811 is much higher ${ }^{36}$ However, this comes at the expense of other stringent requirements of EVs, such as thermal stability (i.e. safety) and capacity retention. For example, a higher Ni content in the NMC cathode cannot only boost the specific energy of electric vehicle batteries but also increases the risk of thermal runaway and decreased cycle life (Fig. 3B). Moreover, Ni-rich cathode materials, e.g. NMC811, incur extra processing costs. Their production, handling and storage (due to their high sensitivity to moisture and air) and their integration at the multi-ton scale present more difficulties than their low Ni content counterparts. NCA shares similarities with NMC811, i.e. delivering high specific energy and power. Although the cyclability of NCA-based cells tends to be better, the 10 wt.\% Co of NCA-based cells is higher than that in NMC811, making them less cost-effective. Nonetheless, increasing the $\mathrm{Ni}$ content of NCA to over $80 \mathrm{wt} . \%$ to boost the cell capacity is still an option that is currently being investigated in the industrial battery research field.

\section{Energy estimation of full cells}

The specific energy $\left(E_{\mathrm{g}}\right)$ and energy $\left(E_{\mathrm{v}}\right)$ density of various cathode materials as a function of the weight fraction of $\mathrm{Si}$ at a fixed areal capacity of $3 \mathrm{mAh} \mathrm{cm}^{-2}$ in a liquid electrolyte (LE) in Si/Si-B/Si-D \| IC cell configurations are depicted in Fig. 4A. For a fixed fraction of $\mathrm{Si}$ (i.e. 60 wt.\%), the energies are found in the order NMC811 NCA $\left(388 \mathrm{Wh} \mathrm{kg}^{-1}, 1087 / 1081 \mathrm{Wh} \mathrm{L}^{-1}\right)>$ LMNO $\left(\mathrm{LiMn}_{1.5} \mathrm{Ni}_{0.5} \mathrm{O}_{2}\right)(364$ $\left.\mathrm{Wh} \mathrm{kg}^{-1}, 1018 \mathrm{Wh} \mathrm{L}^{-1}\right)>\mathrm{NMC532}\left(345 \mathrm{Wh} \mathrm{kg}^{-1}, 977 \mathrm{Wh} \mathrm{L}^{-1}\right)>$ NMC111 (321 Wh kg-1, $\left.925 \mathrm{Wh} \mathrm{L}^{-1}\right)>\mathrm{LCO}\left(304 \mathrm{Wh} \mathrm{kg}^{-1}, 911\right.$ Wh $\mathrm{L}^{-1}$ ), evidencing the promising prospect of $\mathrm{Si}$ (60 wt.\%) $\|$ NMC811 in terms of both $E_{\mathrm{g}}$ and $E_{\mathrm{v}}$. Variation in the Si fraction greatly affects $E_{\mathrm{v}}$ more than $E_{\mathrm{g}}$. Moreover, for $\mathrm{Si}>60$ wt.\%, the gain in energy density with an increasing $\mathrm{Si}$ fraction significantly diminishes.

For commercial applications (EVs and the aviation industry), battery systems require thick electrodes with high specific capacity (i.e. high areal capacity), as they relatively decrease the fraction of non-electroactive materials (e.g. current collectors and separators $)^{40,41}$. Due to the repetitive large volume change associated with $\mathrm{Si}$ anodes and the challenges stemming from ICs (active oxygen release and cation migration), achieving long-term cycling stability at high areal capacities is difficult. For the graphite $\|$ NMC811 cell using LE, the improvement in both $E_{\mathrm{g}}$ and $E_{\mathrm{v}}$ is noteworthy when the areal loading increases up to $\sim 5 \mathrm{mAh} \mathrm{cm}^{-2}$. For areal loadings above $5 \mathrm{mAh} \mathrm{cm}^{-2}$, the contribution is less significant (Fig. 4B). However, in the case of Si||NMC811 batteries, the $E_{\mathrm{g}}$ and $E_{\mathrm{v}}$ values are very sensitive to the areal capacity. The energy density increases up to an areal capacity of $10 \mathrm{mAh} \mathrm{cm}{ }^{-2}$, and the effect of areal capacity is strong up to $80 \mathrm{wt} . \% \mathrm{Si}$, with its influence becoming weaker with higher fractions of $\mathrm{Si}^{42}$. For example, increasing the areal capacity from 5 to $10 \mathrm{mAh} \mathrm{cm}^{-2}$ brings about a $30 \%$ increase in $E_{\mathrm{v}}$, reaching an extremely high value of $\sim 1600 \mathrm{Wh} \mathrm{L}^{-1}$ (Fig. 4B). This highlights the importance of a thick electrode in realising high-energy-density $\mathrm{Si} / \mathrm{Si}$-B/Si-D $\| \mathrm{IC}$ cells (cf. 'Mitigation strategies').

The specific energy and energy density of a Si||NMC811 cell in the presence of different electrolytes, i.e. LE, polymer electrolyte $(\mathrm{PE})$, glassy electrolyte (GE), and ceramic electrolyte (CE), at various fractions of $\mathrm{Si}$ is given in Fig. $4 \mathrm{C}$ for a fixed areal capacity of $3 \mathrm{mAh} \mathrm{cm}^{-2}$. Inorganic solid electrolytes (CE and GE) with a 

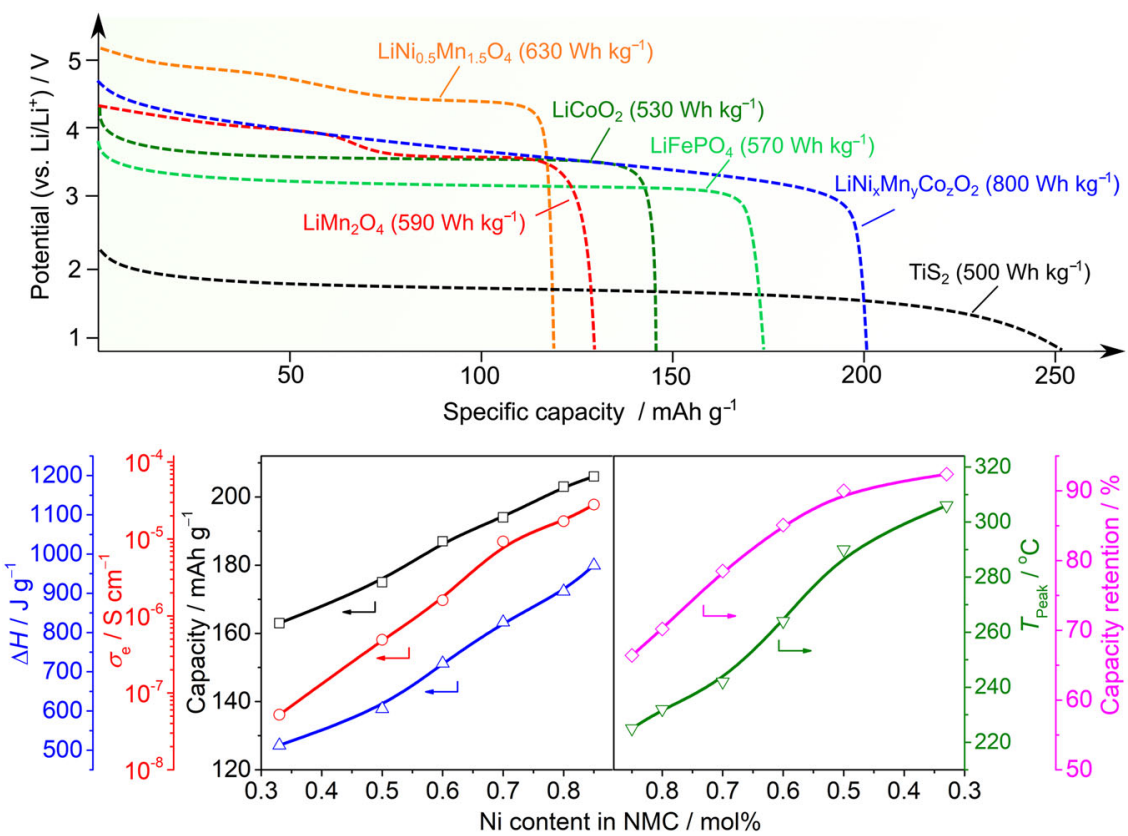

Fig. 3 Cell chemistry of typical insertion cathode materials. Upper plot Discharge profiles (vs. Li-metal anode) of $\mathrm{TiS}_{2}, \mathrm{LiMn}_{2} \mathrm{O}_{4}, \mathrm{LiCoO}_{2}, \mathrm{LiFePO}_{4}$, $\mathrm{LiNi}_{0.5} \mathrm{Mn}_{1.5} \mathrm{O}_{4}$ and $\mathrm{LiNi}_{x} \mathrm{Mn}_{y} \mathrm{Co}_{z} \mathrm{O}_{2}$. The estimated specific energy of each cathode is shown in parentheses, and the values are obtained by simply considering the working voltage of a Li metal|IIC half-cell and the discharge capacity of each cathode. Lower plot Effect of the Ni amount on the discharge capacity, thermal stability (peak temperature $\left(T_{\text {peak }}\right)$ and heat generation $(\Delta H)$ ), capacity retention and electronic conductivity $\left(\sigma_{\mathrm{e}}\right)$ of various NMC materials. Detailed information on these parameters is given in Supporting Table 2.
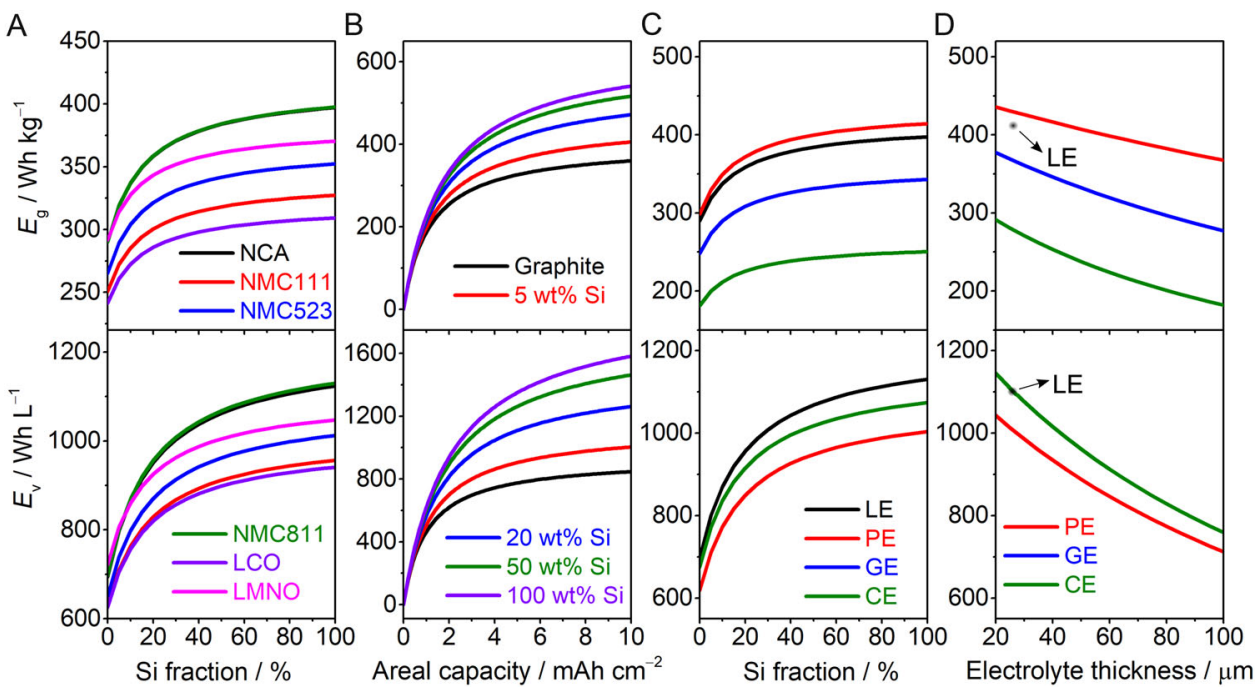

Fig. 4 Estimated specific energy (Eg) and energy density (Ev) values of Si/Si-B/Si-D||IC cells at $25^{\circ} \mathbf{C}$. A Specific energy and energy density vs. Si fraction for LE-based cells at a fixed areal capacity of $3 \mathrm{mAh} \mathrm{cm}{ }^{-2}$. B Specific energy and energy density vs. areal capacity for LE-based cells at various $\mathrm{Si}$ contents. C Specific energy and energy density for Sil|NMC811 cells using various kinds of electrolytes at a fixed areal capacity of $3 \mathrm{mAh} \mathrm{cm}^{-2}$. D Effect of electrolyte thickness on the specific energy and energy density of Si/Gr (20/80, by wt.)||NMC811 cells at a fixed capacity of 5 mAh cm ${ }^{-2}$ (LE liquid electrolyte, PE polymer electrolyte, GE glass electrolyte (LIPON), CE ceramic electrolyte (LLZO)); note that the $E_{\mathrm{v}}$ values for GE and CE overlap in C and D. All the calculation details are in Supporting Tables 3 and 4.

much higher density (e.g. $5.1 \mathrm{~g} \mathrm{~cm}^{-3}$ (CE) vs. $1.9 \mathrm{~g} \mathrm{~cm}^{-3}$ (GE) vs. $1.2 \mathrm{~g} \mathrm{~cm}^{-3}$ (PE) and $\left.1.1 \mathrm{~g} \mathrm{~cm}^{-3}(\mathrm{LE})\right)^{17}$ hardly achieve $E_{\mathrm{g}}$ values higher than $250 \mathrm{Wh} \mathrm{kg}^{-1}$ for $\mathrm{CE}$ and $343 \mathrm{Wh} \mathrm{kg}^{-1}$ for GE. Nevertheless, PE and LE present nearly similar $E_{\mathrm{g}}$ values, reaching 414 and $398 \mathrm{Wh} \mathrm{kg}^{-1}$, respectively. Regarding $E_{\mathrm{v}}$, the four electrolytes present similar values (LE $\left(1130 \mathrm{Wh} \mathrm{L}^{-1}\right)$, GE CE $\left(1074 \mathrm{Wh} \mathrm{L}^{-1}\right)$, and PE $\left.\left(1004 \mathrm{Wh} \mathrm{L}^{-1}\right)\right)$. This suggests that the density of the electrolyte greatly influences the energy density of $\mathrm{Si} / \mathrm{Si}-\mathrm{B} / \mathrm{Si}-\mathrm{D} \| \mathrm{IC}$ cells, particularly $E_{\mathrm{g}}$.

Further estimations of the energies shown in Fig. 4D reveal that the thickness of the electrolyte greatly affects the energy density of $\mathrm{Si} / \mathrm{Si}-\mathrm{B} / \mathrm{Si}-\mathrm{D} \| \mathrm{IC}$ cells, particularly for the CE-based cell. For example, at a fixed electrolyte thickness of $25 \mu \mathrm{m}$, all four types of cells show high $E_{\mathrm{v}}\left(>1000 \mathrm{Wh} \mathrm{L}^{-1}\right)$; however, the CE-based cell 


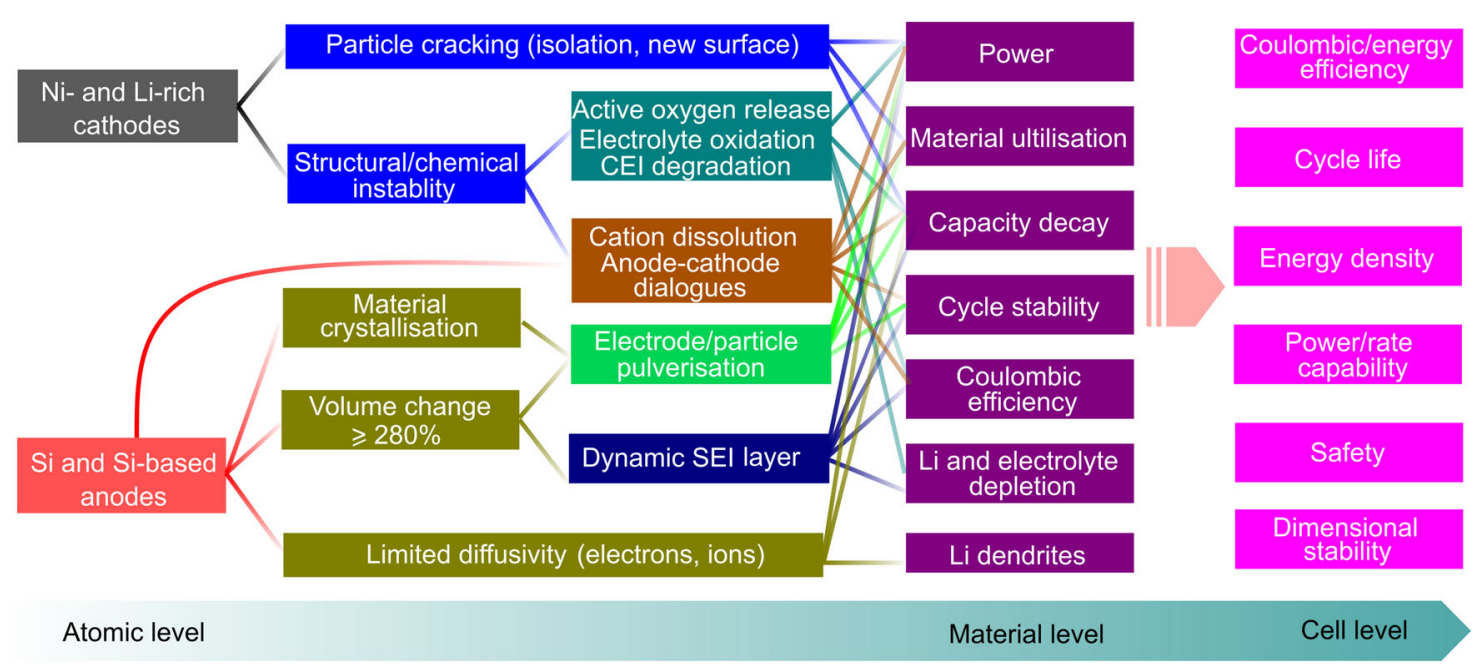

Fig. 5 Correlation between the cell-level performance and atomic/material-level properties for high-energy Si/Si-B/Si-D||IC cells. The main indicators for cell-level performance (e.g. Coulombic/energy efficiency, cycle life, energy density, power/rate capability, safety, dimensional stability) are displayed based on the features of the electrode materials (e.g. power, material utilisation, capacity decay, cycling stability, Coulombic efficiency, Li and electrolyte depletion and Li dendrites). Furthermore, the atomic-level properties (e.g. particle cracking, structural/chemical instability, material crystallisation, volume change and limited diffusivity) that are responsible for the fundamental properties at the material level are described.

has the lowest $E_{\mathrm{g}}$ value of $281 \mathrm{Wh} \mathrm{kg}^{-1}$. This implies that ultrathin CE membranes $(<25 \mu \mathrm{m})$ are vital for achieving respectable $E_{\mathrm{g}}$ values for $\mathrm{CE}$-based cells.

\section{Challenges of $\mathrm{Si} / \mathrm{Si}-\mathrm{B} / \mathrm{Si}-\mathrm{D} \mid \mathrm{IIC}$ cells}

Towards the use of $\mathrm{Si} / \mathrm{Si}-\mathrm{B} / \mathrm{Si}-\mathrm{D} \| \mathrm{IC}$ cells in emerging applications (e.g. EVs and the integration of renewable energy sources), specific energy as well as energy density together with power/rate capability, cycle life, Coulombic/energy efficiency, safety, and cost have to be assessed. These cell-level features are tightly bound to the intrinsic properties of the individual cell components (i.e. anodes, cathodes, binders, conductive additives, electrolytes, etc.) at both the atomic and material levels and their interactions, as illustrated in Fig. 5. While the material-level performances are highly impacted by the atomic-level properties, the atomic-level properties in turn strongly dictate the cell-level performances. Although it is difficult to establish a fine correlation between celllevel performance and atomic-level properties, the intention here is to visualise the possible atomic features that are responsible for the different degradation patterns observed in $\mathrm{Si} / \mathrm{Si}-\mathrm{B} / \mathrm{Si}-\mathrm{D} \| \mathrm{IC}$ cells. Note that the system-level design (e.g. shape/size of the cell, 21,700 vs. 18,650 cells $^{43,44}$ ) is equally important to the individual compartments, but its discussion is beyond the scope of this manuscript.

At the anode side, $\mathrm{Si} / \mathrm{Si}-\mathrm{B} / \mathrm{Si}-\mathrm{D}$-based materials undergo large volume changes during (de)lithiation processes, which may cause electrode/particle pulverisation, resulting in a dynamic SEI (which continuously and reversibly evolves with cycling). Consequently, the efficient implementation of electroactive materials is hindered, in particular with $\mathrm{Li}$, when electrolyte depletion is promoted, worsening the rate capability, cycle stability and Coulombic/energy efficiencies. The very limited diffusivity towards electrons and ions of $\mathrm{Si} / \mathrm{Si}-\mathrm{B} / \mathrm{Si}-\mathrm{D}$ anodes not only results in sluggish kinetics of the redox reaction and capacity decay but also increases the risk of growing $\mathrm{Li}^{0}$ deposits due to the rapid and uneven Li nucleation at the active site of the anode upon fast charging ${ }^{45}$. Bi-phasic crystallisation during the electrochemical lithiation of $\mathrm{Si}$ (Eqs. 1 and 2 for discharging and Eq. 3 for charging) leads to electrode/particle pulverisation, once again resulting in a lower rate capability, poor material utilisation, accelerated capacity decay, and decreased cycle life.

$$
\begin{gathered}
\mathrm{Si}(\text { crystalline })+x \mathrm{Li}^{+}+x \mathrm{e}^{-} \rightarrow \mathrm{Li}_{x} \mathrm{Si} \text { (amorphous) } \\
\mathrm{Si}(\text { crystalline })+(3.75-x) \mathrm{Li}^{+}+(3.75-x) \mathrm{e}^{-} \rightarrow \mathrm{Li}_{15} \mathrm{Si}_{4} \text { (crystalline) } \\
\mathrm{Li}_{15} \mathrm{Si}_{4} \text { (crystalline) } \rightarrow \mathrm{Si} \text { (amorphous) }+\mathrm{yLi}^{+}+\mathrm{ye}^{-}+\mathrm{Li}_{15} \mathrm{Si}_{4} \text { (residual) }
\end{gathered}
$$

At the cathode side, IC materials such as $\mathrm{Ni}$ - and Li-rich oxide cathodes suffer from structural and chemical instability, leading to active oxygen release, electrolyte oxidation on the cathode surface and cathode electrolyte interphase (CEI) degradation. Such factors could accelerate the depletion of both the $\mathrm{Li}$ inventory and the solvent and salt of the electrolyte. This is detrimental to the power, capacity retention and Coulombic/ energy efficiencies of $\mathrm{Si} / \mathrm{Si}-\mathrm{B} / \mathrm{Si}-\mathrm{D}|| \mathrm{IC}$ cells. In addition, acidic species (e.g. $\mathrm{HF}, \mathrm{POF}_{3}$ and $\mathrm{PF}_{5}$ ) generated via electrolyte degradation may dissolve the transition metal cations, causing anode-cathode crosstalk, which in turn leads to the catalytic decomposition of the SEI. This also largely determines the key performance indicator parameters at the material level, thus ultimately affecting the performance of $\mathrm{Si} / \mathrm{Si}-\mathrm{B} / \mathrm{Si}-\mathrm{D} \| \mathrm{IC}$ cells (Fig. 5). On the other hand, the gases formed by electrolyte degradation and/or active oxygen release may mechanically detach active electrode materials from current collectors, expose new surfaces and even lead to particle cracking of electroactive materials $^{46}$. This is deleterious, especially for the power, material utilisation and capacity retention performance of cells.

Despite the recent surge of publications/reports related to $\mathrm{Si} / \mathrm{Si}$ B/Si-D||IC cells, considerable effort has been dedicated to the discovery of new materials and their tests in half-cell setups ( $\mathrm{Si}$ / $\mathrm{Si}-\mathrm{B} / \mathrm{Si}-\mathrm{D} \| \mathrm{Li}$ and $\mathrm{IC} \| \mathrm{Li}$ cells) ${ }^{14,17,24,25}$. Few works have been done on the design and formulation of $\mathrm{Si} / \mathrm{Si}-\mathrm{B} / \mathrm{Si}-\mathrm{D} \| \mathrm{IC}$ full cells, leaving an insurmountable gap for transferring the knowledge and know-how accumulated in laboratories to industrial sectors (a requirement for commercial feasibility) ${ }^{47-49}$. Apart from challenges linked to individual cell components, parameters related to cell design enlisting electrolyte/active material (E/AM, a parameter for quantifying the amount of electrolyte) ratio, negative/positive (N/P ratio, a parameter for quantifying the extra 
capacity of negative electrodes) capacity ratio and data projection from half-cell to full cell must be analysed.

When evaluating the performance of $\mathrm{Si} / \mathrm{Si}-\mathrm{B} / \mathrm{Si}-\mathrm{D} \| \mathrm{IC}$ cells employing flooded electrolyte cell conditions, the Li inventory and N/P ratio is of little significance to improve the technological readiness of new materials discovered in laboratories. Converting the results obtained from half-cells to full cells is not straightforward due to the excessive amounts of $\mathrm{Li}^{0}$ used in half-cells. For instance, a $\mathrm{Li}^{0}$ anode with a thickness of $>50 \mu \mathrm{m}$, which is generally employed for evaluating the electrochemical properties of laboratory-scale $\mathrm{Si} / \mathrm{Si}-\mathrm{B} / \mathrm{Si}-\mathrm{D}$ and IC electrodes ${ }^{17}$, corresponds to a negative electrode capacity that is higher than $10 \mathrm{mAh} \mathrm{cm}-2$. When assuming an achievable positive electrode capacity of 3 $\mathrm{mAh} \mathrm{cm}^{-2}$ for either Si/Si-B/Si-D anodes or Ni-/Li-rich cathode materials, the N/P ratio in the half-cell is always higher than 3.3, which is considerably higher than that in full cells (i.e. N/P ratio $=\sim 1.1$ ). Compared to the full cell, the nearly 'infinite' supply of active $\mathrm{Li}^{+}$ions from the metal anode can sufficiently compensate for the irreversible capacity loss during cycling, which may mask the intrinsic properties of novel materials; as a result, difficulties may arise when projecting data from the halfcell to the full cell.

\section{Mitigation strategies}

To evaluate the strategic solutions for the challenges linked to full cells constructed from $\mathrm{Si} / \mathrm{Si}-\mathrm{B} / \mathrm{Si}-\mathrm{D}$ anodes and ICs, various criteria should be considered for the adequate evaluation of cell performances, namely, energy efficiency, service life (cycle/ calendar life), energy density, rate capability, dimensional stability, safety and cost, which are discussed below.

Redox reaction efficiencies and cycle life. For practical applications such as EVs and consumer electronics, the Coulombic efficiency (CE) and energy efficiency (EE) are crucial metrics to evaluate the electrochemical energy storage performance of a cell, as they correlate to the lifetime and economy of a battery. CE is the most useful parameter dictating the reversibility of cell processes and service life (i.e. cycle life and calendar life) ${ }^{47,50,51}$. CE is defined by $\mathrm{CE}=Q_{\mathrm{d}} / Q_{\mathrm{c}} \times 100 \%=\int_{0}^{t} I_{\mathrm{d}} \mathrm{d} t / \int_{0}^{t} I_{\mathrm{c}} \mathrm{d} t \times 100 \%$, where $Q_{\mathrm{d}}$ and $Q_{c}, t$, and $I$ are the discharge capacity, charge capacity, time and current, respectively. Figure $6 \mathrm{~A}$ illustrates the impact of $\mathrm{CE}$ on the capacity retention of a theoretical Si/Si-B/Si-D || $\mathrm{IC}$ cell, assuming that the $\mathrm{CE}<100 \%$ is completely related to the irreversible loss of active Li. For example, when the CE is $99 \%$, the remaining available Li after 50 cycles is only $60.5 \%$, i.e. $~ 40 \%$ loss of active Li. After 500 cycles, full Si/Si-B/Si-D ||IC cells only deliver $0.66 \%{ }^{49}$ of their original capacity. With the state-of-health ( $\mathrm{SOH}$, here defined as the ratio between the maximum practical capacity and the theoretical capacity of a battery), which is a threshold set at $~ 80 \%$ after 1000 cycles and is required for the practical use of $\mathrm{Si} / \mathrm{Si}-\mathrm{B} / \mathrm{Si}-\mathrm{D} \| \mathrm{IC}$ cells in the electric vehicle industry ${ }^{11,12,21}$, CEs of $99.95 \%$ and above are the target. In addition to the irreversible loss of the Li inventory during each cycle, lower $\mathrm{CE}$ values also imply the consumption of large amounts of electrolyte, leading to electrolyte drying and an increase in impedance. $\mathrm{EE}$, defined as $\mathrm{EE}=$ $\int_{0}^{t_{\mathrm{d}}} V_{\mathrm{d}} I_{\mathrm{d}} \mathrm{d} t / \int_{0}^{t_{\mathrm{c}}} V_{\mathrm{c}} I_{\mathrm{c}} \mathrm{d} t \times 100 \%$ (where $V_{\mathrm{d}}$ and $V_{\mathrm{c}}$ represent the average discharge and charge voltages, respectively), is another crucial parameter of battery materials that generally tends to go unnoticed ${ }^{50}$. The energy efficiency differs from material to material for anodes: graphite $(\sim 94 \%)>$ soft carbon $(93 \%)>$ silicon/graphite ( $\sim 89 \%)$; and cathodes: LNMO $(\sim 97 \%) \geq$ NMC $(96 \%) \geq$ LR-NMC $(\sim 85 \%)^{52}$. Achieving high CE in Si/Si-B/Si-D IC cells involves circumventing issues in both the anode and cathode compartments. Owing to the high degree of sensitivity of $\mathrm{CE}$, its improvement affects the cell cycle life and the improvement of EE. The strategies for improving the $\mathrm{CE}$ and $\mathrm{EE}$ can be summarised by several approaches, including electrolyte development, electrode design, pre-lithiation, polymeric binders and conductive additives. However, only the critical factors are discussed below.

Electrolyte design. Incorporating a small dose of salt and/or molecular additives $(\leq 10 \%$ by wt. or vol.; e.g. vinylene carbonate (VC), fluoroethylene (FEC)) into the electrolyte solution is hailed as the most efficient, economical and scalable strategy to combat the very large volume changes as well as the unstable SEI/CEI layer ${ }^{14}$. To avoid the complexity linked to the use of a mixture of various electrolyte additives usually adopted in commercial LIBs, the design of multifunctional electrolyte constituents is of paramount importance, particularly for Si/Si-B/Si-D||IC cells. The development of additives that possess either multiple functionalities or tailored synergistic effects is required to enable $\mathrm{Si} / \mathrm{Si}-\mathrm{B} /$ Si-D |IC battery systems. In view of the various methods to boost the $\mathrm{CE}$, electrolyte additives can be categorised into different classes (Fig. 6B): (1) surface chemistry (SEI and CEI layers) modifiers, (2) acidic/protonic species scavengers, and (3) reactive species/molecules trappers/transformers.

To enable the practical application of $\mathrm{Si} / \mathrm{Si}-\mathrm{B} / \mathrm{Si}-\mathrm{D} \| \mathrm{IC}$ cells, SEI/CEI-forming additives are indispensable to improve their cyclability by suppressing parasitic reactions related to electrodeelectrolyte interphases. Such additives possess electrochemically reducible and oxidisable functional moieties ${ }^{53}$. Designer additives used as precursors to build robust SEI/CEI should result in compounds with (1) a high shear modulus, which is essential for boosting the mechanical/chemical stabilities ${ }^{54}$; (2) a low alkalinity/basicity (i.e. low acid-base reactivity), which is critical for suppressing the chemical and electrochemical degradations of electrolytes and electrodes ${ }^{55}$; (3) high $\mathrm{Li}^{+}$transport and negligible diffusion of electrons and electrolyte; and (4) a low solubility in alkyl carbonate solvents, which is beneficial for reducing the reactivity of acidic species and other trace impurities $\left(\mathrm{HF}, \mathrm{POF}_{3}\right.$, $\mathrm{H}_{2} \mathrm{O}, \mathrm{PF}_{5}$, among others $)^{56}$. In general, electrolyte additives are depleted during each cycle; hence, their early effect (e.g. building the SEI/CEI) should provide sustained benefits throughout the cycling process.

Figure $6 \mathrm{C}$ displays a variety of electrolyte additives proven to effectively enhance the $\mathrm{CE}$ of $\mathrm{Si} / \mathrm{Si}-\mathrm{B} / \mathrm{Si}$-D ||IC full cells. Although widely used as film additives, VC possesses high impedance, thus exhibiting a poor rate capability, as well as serious gas evolution. However, when FEC is used, rapid consumption of the electrolyte additive at elevated temperatures occurs ${ }^{57,58}$. Lewis acid-induced defluorination of FEC results in the formation of reactive species (e.g. $\mathrm{HF}, \mathrm{HPO}_{2} \mathrm{~F}_{2}$ ), damaging the SEI/CEI and shortening the lifetime of the battery ${ }^{59}$. Trifluoropropylene carbonate (TFPC) possesses an electron-withdrawing trifluoromethyl group that is capable of improving the cycling stability by regulating the structure and composition of the interphases, outperforming FEC $^{60}$

Molecular additives containing $\mathrm{Si}-\mathrm{O}$ moieties such as silanes and their derivatives play multiple roles by forming $(-\mathrm{O}-\mathrm{Si}-\mathrm{O}-)_{n}$ polymer-derived passivation layers, scavenging $\mathrm{HF}$ among other acidic species due to the strong affinity of $\mathrm{HF}$ to $\mathrm{Si}$. $-\mathrm{N}=\mathrm{C}=\mathrm{O}$ containing additives form a robust SEI/CEI layer and capture trace amounts of $\mathrm{HF}$ and water in electrolyte solutions (Fig. 6D) ${ }^{61}$. Nitrile $(-\mathrm{C} \equiv \mathrm{N})$-functionalized silane (e.g. 2-cyanoethyl triethoxysilane (TEOSCN)) forms highly conductive and mechanically stable SEI/CEI layers, leading to an improvement in performance at elevated temperatures $\left(45^{\circ} \mathrm{C}\right.$, starting temperature for the 
A

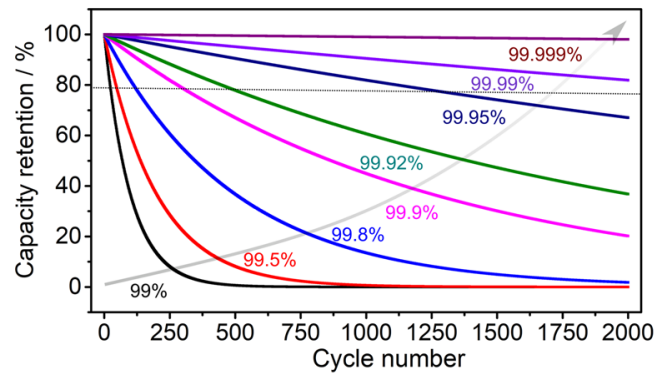

C
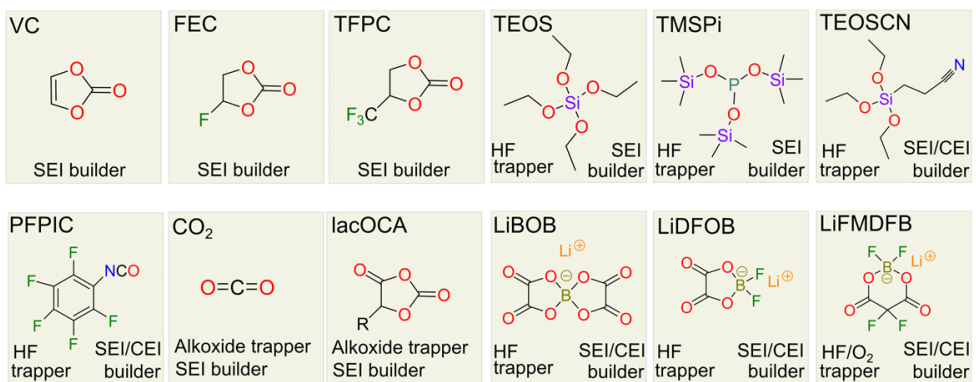

B

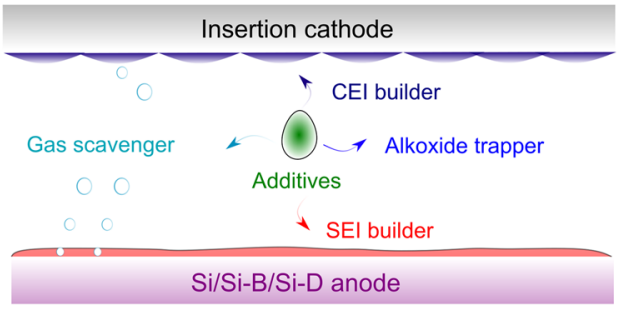

D

E

Van der Waals $(<20)$

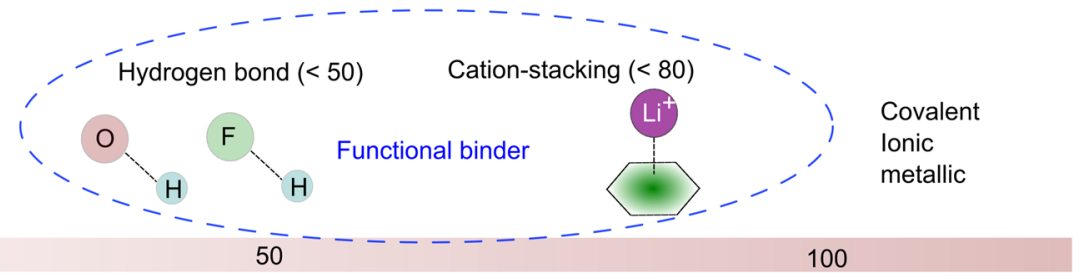

0
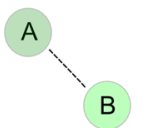

$\mathrm{F}$

F

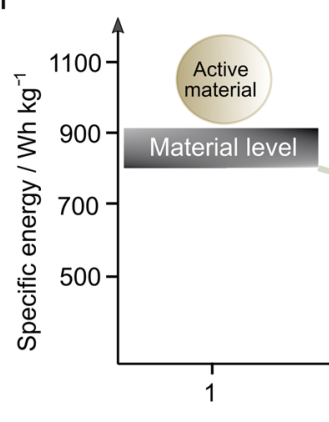

Bond energy $/ \mathrm{kJ} \mathrm{mol}^{-1}$

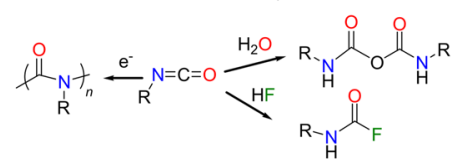


interphase building compounds rich in $\mathrm{LiF}$ and $\mathrm{Li}_{3} \mathrm{~N}$; hence, they are potential candidates for $\mathrm{Si} / \mathrm{Si}-\mathrm{B} / \mathrm{Si}-\mathrm{D} \| \mathrm{IC}$ cells.

Pre-lithiation. Pre-lithiation, referring to the incorporation of active $\mathrm{Li}$ into the cell (mainly at the negative electrode in the case of Si/Si-B/ Si-D||IC cells) before operation, is of particular interest to LIB manufacturers ${ }^{71}$. Presently, the main pre-lithiation routes include ex situ or in situ electrochemical pre-lithiation, chemical prelithiation by active reactants, direct contact with metallic $\mathrm{Li}$, prelithiation with electrode additives (both on negative and positive electrodes), and overcharged cathodes. For practical applications, the pre-lithiation approach should be simple, scalable, cost-effective, and safe. The pre-lithiation compound(s) should fulfil the following requirements: (1) possess high 'donor' lithium-ion capacity during the initial charge/discharge steps with no negative effects on electrochemical performance, such as cycle life and rate capability; (2) offer a controllable pre-lithiation degree, critical for matching the capacity between the cathode and anode; (3) have good compatibility with existing battery fabrication processes, i.e. drop-in technology; and (4) have low cost and high safety ${ }^{72}$. However, most of the reagents proposed thus far require processing in a dry atmosphere, which substantially increases the cost of cell production.

Design of polymeric binders. The use of custom-built polymeric binders is another appealing approach ${ }^{73,74}$. Due to the huge mechanical stress caused by the large volume change of $\mathrm{Si} / \mathrm{Si}-\mathrm{B} / \mathrm{Si}-\mathrm{D}$ anodes, the binding actions fail upon cycling, leading to particle pulverisation and uncontrollable growth of the electrode/electrolyte interphases. The harsh conditions (e.g. large volume change associated with anode and cation dissolution and oxygen release on the cathode) linked to the use of Si/Si-B/Si-D |IC cells infer that the knowledge accumulated from state-of-the-art anodes (e.g. graphite and $\mathrm{Li}_{4} \mathrm{Ti}_{5} \mathrm{O}_{12}$ ) and cathodes (e.g. $\mathrm{LiCoO}_{2}$ and low $\mathrm{Ni}$ variants of NMC) may not be useful. Hence, the binder development for Si/Si-B/ $\mathrm{Si}-\mathrm{D}|| \mathrm{IC}$ needs to be addressed from a new perspective. The adhesive property of polymeric binders is closely related to their chemical nature, associated mode of interactions and nature of active materials as well as carbon conductive additives. For chemistries experiencing very large volume changes, polymeric binders with strong yet reversible interactions are important ${ }^{14}$. This aspect highlights the necessity of balancing the bond strength and reversibility (bond recovery) of the desired binder molecules. Figure $6 \mathrm{E}$ depicts the different bonding strengths and comfort zones for the development of potential binders for $\mathrm{Si} / \mathrm{Si}-\mathrm{B} / \mathrm{Si}-\mathrm{D}|| \mathrm{IC}$ battery systems. In the development of tailored polymeric binders, reactive functional groups such as $-\mathrm{OH},-\mathrm{COOH}$, and $-\mathrm{NH}_{2}$, which are capable of forming strong hydrogen bonds, ion-dipole interactions, and even chemical bonds that are far stronger than van der Waals forces, play a crucial role $^{73,74}$.

Particle and alloy engineering. The electrochemical performance of $\mathrm{Si}, \mathrm{Si}-\mathrm{B}$ and $\mathrm{Si}-\mathrm{D}$ anodes is greatly influenced by $\mathrm{Si}$ particle size, surface area, surface oxygen content, hydroxyl $(-\mathrm{OH})$ content, and morphology. For instance, the ICE is inversely correlated with surface area and oxygen content. Thus, surface modification/treatment along with alloy formation decreases the irreversible capacity loss and improves the Coulombic and energy efficiencies by mitigating volume expansion and minimising the surface area (https://projects.leitat.org/wp-content/uploads/2016/11/4-3M-Sialloy-material-for-next-Generation-Li-ion.pdf). For IC-type positive electrodes, particle size and surface composition are important in regard to their electrochemical properties. Approaches include the utilisation of sub-micro and nano-sized particles, single crystals and electrolyte-compatible surface coating layers, have been proven to be effective ${ }^{36,75}$.
Evaluation of energy and power performances at the cell level. Specific energy and energy density are the most important parameters used to assess LIB cells because they consider not only cell capacity and voltage but also the weight and volume of all active/ inactive components ${ }^{76}$. In general, the target-specific energy and energy density can be estimated via the top-down approach slicing from the pack level to the electrode and/or material level using inhouse developed calculation tools ${ }^{77}$ or by the bottom-up approach starting from theoretical values ${ }^{78}$. Realistic values for the energy density of $\mathrm{Si} / \mathrm{Si}-\mathrm{B} / \mathrm{Si}-\mathrm{D}$-based electrodes have to be considered in the lithiated state; hence, the displaced electrolyte volume and single electrode energy density cannot be measured in practice without considering the counter electrode ${ }^{42,79}$. As discussed in the 'Energy density estimation of full cell' section, the achievable energy density of $\mathrm{Si} / \mathrm{Si}-\mathrm{B} / \mathrm{Si}-\mathrm{D}|| \mathrm{IC}$ cells is associated with several parameters at the material level. To date, substantial efforts have been devoted to the nano-structural design of Si/Si-B/Si-D anodes aiming to improve $\mathrm{Li}^{+}$and $\sigma_{\mathrm{e}-}$ diffusivity and reduce volume change ${ }^{16}$. The high specific energy/energy density and rate capability of $\mathrm{Si} / \mathrm{Si}-\mathrm{B} / \mathrm{Si}-\mathrm{D}$ anodes have been extensively reported in recent years, reaching high areal loadings and capacities $\left(>10 \mathrm{mg} \mathrm{cm}^{-2}\right.$ and $>10 \mathrm{mAh} \mathrm{cm}^{-2}$ ) and extremely high C-rates $(10 \mathrm{C})^{80-90}$. However, most of the results are obtained from the testing of laboratory-scale cells assembled in electrolyte-flooded conditions (i.e. $\mathrm{E} / \mathrm{AM}>5$ ) and using a Li-metal electrode as the counter electrode (i.e. half-cell setup with $\mathrm{N} / \mathrm{P}>3)^{11,12,21}$.

Considering the ambiguous use of 'specific energy and energy density' within the research of Si/Si-B/Si-D || $\mathrm{IC}$ cells (i.e. misuse of energy values obtained at different calculation levels), it is necessary to give an explicit definition of this term depending on the technology readiness level (TRL). Figure 6F schematically portrays the evolution of energy density from a low TRL (i.e. materials discovery and testing in laboratory research) to a high TRL (industrial battery pack assembly). At the material level, a number of enticing values have been reported in the literature, such as high specific energy of $700 \mathrm{Wh} \mathrm{kg}^{-180}$. However, these values decrease drastically after shifting to the cell level when the mass of the electrolyte, separator, current collectors, and conductive additives are included in the calculation of the specific energy and energy density (see Supporting Fig. 1 for details). In general, various factors can be discounted when translating the $\mathrm{Si}$ electrode specific capacity to the practical specific energy and energy density of a Si/Si-B/Si-D $\|$ IC cell. Our calculations and those from other groups ${ }^{84}$, indicate that an improvement of $>20 \%$ in terms of specific energy and energy density can be achieved for $\mathrm{Si} / \mathrm{Si}-\mathrm{B} / \mathrm{Si}-\mathrm{D}|| \mathrm{IC}$ cells compared to current Li-ion cell technology.

With very limited information related to the porosity of the electrode and density of each component, it is very difficult to estimate the specific energy and energy density, thereby leading to difficulty in expounding the power/rate capabilities at the cell level for the results reported in the literature. Although recent reports have included key parameters such as the E/AM and N/P ratios, along with the areal capacity ${ }^{88-91}$. It must be stressed that transversal comparison between the specific energy/energy density and rate/power capabilities at the cell level can only be made when all the essential components (Fig. 6F) of the cell are considered for calculating the specific energy and energy density. Herein, we recommend the consideration of the following parameters as compulsory when reporting new results related to $\mathrm{Si} / \mathrm{Si}-\mathrm{B} / \mathrm{Si}-\mathrm{D} \| \mathrm{IC}$ cells:

1. Electrode materials: mass percentage and density of the individual components (active materials) within the electrode; porosity, thickness, mass loading and nominal capacity of active material.

2. Electrolyte and separator: density and volume of electrolyte filled for each cell, thickness and density of separator. 


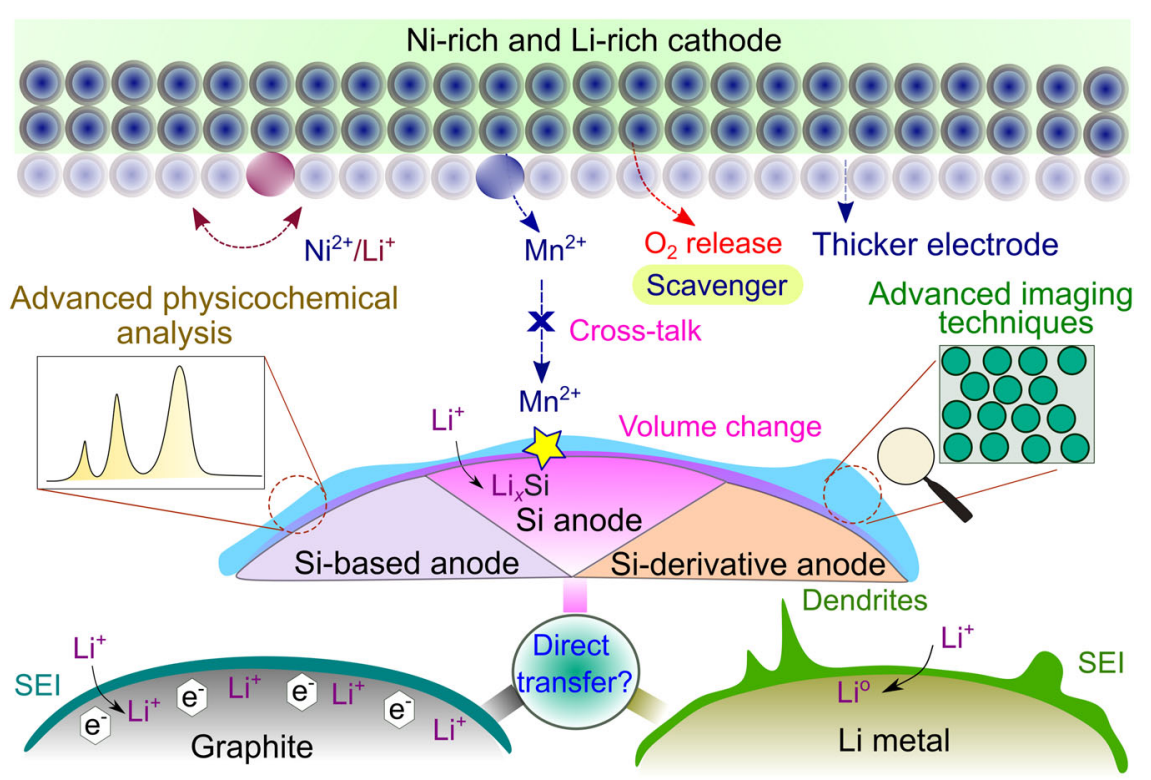

Fig. 7 Challenges and solutions for Si/Si-B/Si-D||IC cells. To implement this technology commercially, Si/Si-B/Si-D anodes suffer from a very large volume change, with ICs mostly hindered by their chemical/electrochemical instability (e.g. cation displacement, dissolution of transition metal ions, release of reactive oxygen, etc.). Shifting from the atomic/material level to the cell level, crosstalk between anode and cathode materials during continuous cycling and thick electrodes are required for high-energy batteries, although this may impose additional challenges for stabilising electrode/electrolyte interphases. In addition, the direct transfer of knowledge attained from graphite and Li metal-based rechargeable batteries to $\mathrm{Si} / \mathrm{Si}$-B/Si-D/|IC systems is not straightforward. Solutions may involve advanced physicochemical analysis and imaging techniques to understand anode-electrolyte interphases as well as scavengers for capturing $\mathrm{O}_{2}$ gas.

3. Other relevant parameters: $\mathrm{N} / \mathrm{P}$ ratio, details related to current collectors, and cell configurations.

Safety-induced risks. The large-scale deployment of LIB cells necessitates the appraisal of safety-induced risks, including the heat release rate (HRR), enthalpy of combustion $\left(\Delta H_{c}\right)$, and release and dose of toxic products, under various abuse conditions. The legitimate questions associated with $\mathrm{Si} / \mathrm{Si}-\mathrm{B} / \mathrm{Si}-\mathrm{D} \| \mathrm{IC}$ cells could be as follows: how do the intrinsic (linked to the properties of the material, such as the easily breakable SEIs of Si/ $\mathrm{Si}-\mathrm{B} / \mathrm{Si}-\mathrm{D}$ and structural instability of ICs) safety issues of $\mathrm{Si} / \mathrm{Si}-\mathrm{B} /$ $\mathrm{Si}-\mathrm{D}$ anodes and $\mathrm{Ni} / \mathrm{Li}$-rich/high-voltage cathodes affect the safety of $\mathrm{Si} / \mathrm{Si}-\mathrm{B} / \mathrm{Si}-\mathrm{D}|| \mathrm{IC}$ full cells; how does the low diffusivity of $\mathrm{Li}^{+}$ ions and electrons in a $\mathrm{Si} / \mathrm{Si}-\mathrm{B} / \mathrm{Si}-\mathrm{D}$ anode, compared to those in $\mathrm{Gr}$ electrodes, delay the thermal runaway; and how does the large volume change, electrode swelling and instability of the SEI layer affect the safety issues of practical $\mathrm{Si} / \mathrm{Si}-\mathrm{B} / \mathrm{Si}-\mathrm{D}$ anode-based full cells? The answers to the above questions and related (intriguing) queries require a thorough understanding of the safety-related patterns of the individual electrodes and full cells, making use of various analytical tools.

Material to cell cost. The overall cost of $\mathrm{Si} / \mathrm{Si}-\mathrm{B} / \mathrm{Si}-\mathrm{D} \| \mathrm{IC}$ originates from the raw sources, synthesis and processing, electrolytes, binders, current collectors, conductive additives, formation stages and other factors. From the anode side, although Si precursors are inexpensive (e.g. $\mathrm{SiO}_{2}$ ), the cost linked to the large-scale production of realistic $\mathrm{Si} / \mathrm{Si}-\mathrm{B} / \mathrm{Si}-\mathrm{D}$-containing cells could pose a major challenge. A high abundance of economical starting materials does not necessarily mean that the final product is market competitive. For instance, the large-scale production of nano-Si demands a complex process with sophisticated techniques; therefore, it is pricier than upstream materials such as $\mathrm{SiO}_{x}$ nano-silica, micro-Si, metallurgical $\mathrm{Si}$ wafers and $\mathrm{Si}$ from rice husk (negligible price) $24,50,92$. From the cathode perspective, the cost related to $\mathrm{Co}$ and $\mathrm{Ni}$ in IC materials as well as large-scale manufacturing is a pressing issue $\mathrm{e}^{15,93}$.

Importantly, in addition to the active materials and associated costs, electrolyte wetting and SEI/CEI formation are among the most expensive steps in battery production ecosystems ${ }^{94,95}$. Because of slow wetting and charge/discharge rates, electrode processing and wetting/formation costs are 2.2 and $7.5 \$ \mathrm{~kW} \mathrm{~h}^{-1}$, respectively. Depending on the cell manufacturer, cell chemistry and other factors (e.g. temperature), this process can take 15-21 days, demanding a large amount of floor space as well as large amounts of consumed energy for the cyclers and environmental chambers ${ }^{96}$. The electrode processing and wetting/formation processes, particularly for Sil|IC cells, are detrimental features towards the overall cost and need ample attention. Overall, the economic estimation of Si/Si-B/Si-D ||IC cells demands a holistic approach as well as a meticulous assessment of the overall cost of LIB production.

\section{Summary and outlook}

In consideration of their potential advantages, such as their low cost, environmental benignity, and high energy, batteries built on $\mathrm{Si}, \mathrm{Si}-\mathrm{B}$ and/or Si-D coupled with IC are gaining exceptional momentum. However, combined approaches and solutions with synergistic effects are needed to overcome the obstacles associated with $\mathrm{Si} / \mathrm{Si}-\mathrm{B} / \mathrm{Si}-\mathrm{D} \| \mathrm{IC}$ cells. Figure 7 schematically presents the critical factors that need to be contemplated as guidelines along with the solutions for the incorporation of these systems. For the development of practical $\mathrm{Si} / \mathrm{Si}-\mathrm{B} / \mathrm{Si}-\mathrm{D}|| \mathrm{IC}$ cells, the following criteria are suggested as future directions to boost the practical performance metrics required by battery manufacturers.

\section{Material-level design}

Selection and elaboration of electrode materials. Considering the overall cell performance of $\mathrm{Si} / \mathrm{Si}-\mathrm{B} / \mathrm{Si}-\mathrm{D}|| \mathrm{IC}$ cells, $\mathrm{Si} / \mathrm{Gr}$ with $\mathrm{Si} \approx$ 
40 wt.\%, $\mathrm{SiO} / \mathrm{Gr}$ and $\mathrm{SiN}_{x} / \mathrm{C}$ blend/composite anodes along with $\mathrm{Ni} / \mathrm{Li}$-rich cathode materials could be regarded as materials of choice. Due to the extra embedded Li, Li-rich cathode materials coupled with $\mathrm{Si} / \mathrm{Si}-\mathrm{B} / \mathrm{Si}-\mathrm{D}$ are also worth investigating. Regarding the anode side, surface coating/modification, surface engineering plus tuning morphologies could be developed. Regarding the cathode side, strategies including examining critical synthesis conditions, electrode modification and regulating the interphases could be further explored.

Electrolyte additives and salt anions. The development of molecular and/or salt-type additives with multiple functionalities and/ or synergistic effects is important to advance the performance of future $\mathrm{Si} / \mathrm{Si}-\mathrm{B} / \mathrm{Si}-\mathrm{D}|| \mathrm{IC}$ cell generations. To speed up the discovery of novel electrolyte additives and salt anions, high-throughput screening methods via combined theoretical, electrochemical, and spectroscopic methods are in great demand.

Design of polymeric binders. Binders with abundant $-\mathrm{O}-$ or $-\mathrm{N}-$ and highly polarised moieties such as $-\mathrm{COOH},-\mathrm{OH}$, and $-\mathrm{NH}_{2}$ bestow moderately strong but elastic (reversible/self-healing) supramolecular interactions such as hydrogen bonding, ion-ion interactions, ion-dipole interactions, etc. In addition, in-depth research on structure (bond strength)-property correlations could further elucidate the working mechanisms of these binders in $\mathrm{Si} /$ $\mathrm{Si}-\mathrm{B} / \mathrm{Si}-\mathrm{D} \| \mathrm{IC}$ cells.

Current collectors. For high areal capacity electrode materials, their efficient implementation requires physical contact between the electrode coatings and current collectors. Replacing flat current collectors with three-dimensional architectures obtained from cost-effective approaches could functionally increase the contact area and promote the transport of electrons within thick electrodes, improving the capacity and cyclability of these highenergy cells. As a result, the dedicated effort is needed for the design and elaboration of current collectors for $\mathrm{Si} / \mathrm{Si}-\mathrm{B} / \mathrm{Si}-\mathrm{D} \|$ IC cells.

Active material structuring. Building a stable electrode structure is among the most effective approaches to enable the practical application of Si- and Si-based LIBs as well as derivative anodebased $\mathrm{LIBs}^{97-99}$. This includes Si nanoparticles (NPs), 3D architectures, aligned nanowires/nanotubes, dispersal of $\mathrm{Si}$ into an active matrix, Si-based thin films, and free standing and other tailored morphologies. The engineering of $\mathrm{Si}$ nanostructure materials, including 0-dimensional (0D) nanoparticles, 1D nanowires, 2D nanosheets, and 3D hierarchical nanostructures, has been proven to be an effective strategy to reduce the massive volume change of $\mathrm{Si}$ and improve the interaction between $\mathrm{Si}$ active materials and electrolytes due to the larger surface area ${ }^{100}$. Nano-sized Si particles further promote electrical conductivity by shortening the transport distance for $\mathrm{e}^{-/ \mathrm{Li}^{+}}$and reducing the inhomogeneous lithium diffusion-induced stress and strain. However, nanoparticles also induce accelerated electrolyte decomposition and thickening of the SEI, resulting in high impedance, decreased ICE, and poor thermal stability; all of the above cumulatively limits their future commercial viability ${ }^{100}$. It is noteworthy to mention that the above strategies have only been demonstrated at the laboratory scale.

Processing of electrode and electrolyte materials. The cell-level processing of both $\mathrm{Si} / \mathrm{Si}-\mathrm{B} / \mathrm{Si}-\mathrm{D}$ anodes and IC materials plays a key role in designing high-performance electrochemical energy storage devices. These entail optimisation of slurry formation and electrode processing, electrolyte formulation, and the N/P ratio, particularly towards the implementation of thick electrodes, which are critical for achieving sufficient energies. In short, process optimisation, cell testing conditions and protocols at different levels are important to transpose laboratory results into commercial devices.

Pre-lithiation. Pre-lithiation via the addition of scalable and safe materials acting as lithium-ion donors appears to be the most promising approach to boost the practical energies of $\mathrm{Si} / \mathrm{Si}-\mathrm{B} / \mathrm{Si}$ D ||IC cells. This may finally lead to the commercial implementation of such high-capacity anode materials (i.e. Si content $>10$ wt.\%).

Half-cells to full cells data transfer and reporting. The electrochemical energy storage performance discrepancy between the laboratory-scale half-cells and full cells is remarkable for $\mathrm{Si} / \mathrm{Si}-\mathrm{B} /$ $\mathrm{Si}-\mathrm{D}$ negative electrodes and IC positive electrodes. Unlike the infinite access of cyclable $\mathrm{Li}^{+}$ions supplied from the metal anode in half-cells, the supply in full cells is limited by the capacity of the cathode. The consumption of cyclable $\mathrm{Li}^{+}$from parasitic (side) reactions results in notable capacity losses in full cells compared to half-cells. Aside from the Li inventory, issues such as electrolyte drying out and optimisation of the N/P ratio also hinder the practicality of full cells. Consequently, accurate and complete data reporting would accelerate the projection of laboratory results into industry-implemented values.

Lessons from current research: out-of-the-box thinking for the future. Although the inspiration and knowledge gained from the present LIBs can provide insights to improve the understanding of high-energy $\mathrm{Si} / \mathrm{Si}-\mathrm{B} / \mathrm{Si}-\mathrm{D} \| \mathrm{IC}$ cells, there is no guarantee that the accumulated knowledge can be transferred. The lack of standard testing protocols for laboratory-based investigations leads to hyperboles; approaches used in one system may not be applicable to evaluate new battery materials and technologies. The technology (in general), the screening of additives, polymeric binders, electrode design/engineering and utilisation of half/full cells calls for out-of-the-box thinking for new methodologies.

System consideration: anode-cathode crosstalk. The interfacial processes and associated chemistries occurring at the polarised electrodes, electrolyte and formed interphases are usually considered isolated from each other. However, ever-increasing evidence discloses that certain forms of crosstalk exist between them. This is because the species generated on one electrode often appear on the other compartment with unforeseen detrimental effects. This issue becomes critical with $\mathrm{Si} / \mathrm{Si}-\mathrm{B} / \mathrm{Si}-\mathrm{D}|| \mathrm{Ni} / \mathrm{Li}$-rich batteries because both electrode compartments are endowed with harsh (electro)chemical conditions (e.g. an unstable SEI layer on the anode and active oxygen release on the cathode). Low potential (e.g. $0.2 \mathrm{~V}$ vs. $\mathrm{Li} / \mathrm{Li}^{+}$) lithiation processes cause an increase in the predetermined voltage of the cathode upon repeated cycling, resulting in decreasing cycling efficiencies, promoting capacity fade and increasing impedance. Hence, the design of high-energy $\mathrm{Si} / \mathrm{Si}-\mathrm{B} / \mathrm{Si}-\mathrm{D} \| \mathrm{IC}$ cells entails a systemic and detailed study of the crosstalk between electrodes, electrolytes and interphases along with their complex chemistries.

Advanced physicochemical analysis and imaging techniques. Despite the vast interest in the coupling of high-capacity $\mathrm{Si} / \mathrm{Si}-\mathrm{B} /$ Si-D and IC electrodes, a detailed understanding of the underlying active/inactive mechanisms under practical conditions remains unknown. Despite the synergistic positive effect due to coupling, understanding such processes requires advanced physicochemical analytical tools. In consideration of the harsh 
conditions on both compartments and their possible crosstalk, an in-depth fundamental study using real-time in situ experimental techniques coupled with theoretical calculations is necessary. Making use of sub-molecular and atomic-level simulations assisted by the further discovery of optimisation strategies is of paramount importance to transition towards their commercialisation. The failure mechanisms deriving from changes in the chemical composition, morphology and crystal structure of electrochemically active components still require a basic understanding.

Finally, the authors would like to propose the following openended questions to the scientific community to help improve understanding and to tackle some of the challenges linked to Sicontaining/derivative anodes and IC cathodes.

1. Considering the high operating potential and massive volume change associated with $\mathrm{Si}$, what will be the real contribution of $\mathrm{Si}$ and $\mathrm{SiO}$ in $\mathrm{Si}-\mathrm{Gr}$ and $\mathrm{SiO}-\mathrm{Gr}$ blends/ composites, respectively, towards the practically obtainable energy density in terms of the driving range of EVs?

2. How does the large volume change of Si-based electrodes affect the volumetric energy of the full cells? How does the cathode respond to the large volume change of $\mathrm{Si}$ ?

3. How does the fraction of incoming $\mathrm{Li}^{+}$from pre-lithiated $\mathrm{Si}-\mathrm{Gr}$, and $\mathrm{Si} / \mathrm{SiO}$ blend/composite electrodes compare for $\mathrm{Gr}, \mathrm{Si}$ and $\mathrm{SiO}$, in relation to an identical non-prelithiated cell?

4. What are the governing failure mechanisms of Si-Gr and $\mathrm{SiO} / \mathrm{Gr}$ blend/composite electrodes from short- and longterm cycling perspectives, particularly in full cell configurations?

5. How does the amount of nitrogen and/or Si affect the capacity, cyclability, chemical and electrochemical stability of the conversion and alloying reactions?

6. How does the cation migration and active oxygen release from ICs affect the volume change associated with $\mathrm{Si}$, Sibased and Si-derivative materials in full cell configurations?

7. How does a single crystal IC-type positive electrode affect the overall properties of a full cell?

In conclusion, high-energy-density $\mathrm{Si} / \mathrm{Si}-\mathrm{B} / \mathrm{Si}-\mathrm{D} \| \mathrm{IC}$ cells have received significant attention from both the academic and industrial research communities. With extensive innovative $\mathrm{R} \& \mathrm{D}, \mathrm{Si} / \mathrm{Si}-\mathrm{B} / \mathrm{Si}-\mathrm{D} \| \mathrm{IC}$ cells could be deemed as future generation technologies for use in emerging large-scale applications, such as their use in EVs and for the efficient integration of renewable energy sources.

Received: 2 December 2020; Accepted: 26 July 2021;

Published online: 15 September 2021

\section{References}

1. Armand, M. \& Tarascon, J.-M. Building better batteries. Nature 451, 652-657 (2008).

2. Dunn, B., Kamath, H. \& Tarascon, J.-M. Electrical energy storage for the grid: a battery of choices. Science 334, 928-935 (2011).

3. Eshetu, G., Armand, G. G., Scrosati, B. M. \& Passerini, S. Energy storage materials synthesized from ionic liquids. Angew. Chem. Int. Ed. 53, 13342-13359 (2014).

4. Winter, M. \& Brodd, R. J. What are batteries, fuel cells, and supercapacitors? Chem. Rev. 104, 4245-4270 (2004).

5. Nitta, N., Wu, F., Lee, J. T. \& Yushin, G. Li-ion battery materials: present and future. Mater. Today 18, 252-264 (2015).

6. Placke, T., Kloepsch, R., Dühnen, S. \& Winter, M. Lithium ion, lithium metal, and alternative rechargeable battery technologies: the odyssey for high energy density. J. Solid State Electrochem. 21, 1939-1964 (2017).
7. Bresser, D. et al. Perspectives of automotive battery R\&D in China, Germany, Japan, and the USA. J. Power Sources 382, 176-178 (2018).

8. Lu, Y., Zhang, Q. \& Chen, J. Recent progress on lithium-ion batteries with high electrochemical performance. Sci. China Chem. 62, 533-548 (2019).

9. Zhang, H. et al. From solid solution electrodes and the rocking-chair concept to today's batteries. Angew. Chem. Int. Ed. 59, 534-538 (2019).

10. Eshetu, G. G., Mecerreyes, D., Forsyth, M., Zhang, H. \& Armand, M. Polymeric ionic liquids for lithium-based rechargeable batteries. Mol. Syst. Des. Eng. 4, 294-309 (2019).

11. Marinaro, M. et al. Bringing forward the development of battery cells for automotive applications: perspective of R\&D activities in China, Japan, the EU and the USA. J. Power Sources 459, 228073 (2020).

12. Schmuch, R., Wagner, R., Hörpel, G., Placke, T. \& Winter, M. Performance and cost of materials for lithium-based rechargeable automotive batteries. Nat. Energy 3, 267-278 (2018).

13. Zeng, X. et al. Commercialization of lithium battery technologies for electric vehicles. Adv. Energy Mater. 9, 1900161 (2019).

14. Eshetu, G. G. \& Figgemeier, E. Confronting the challenges of next-generation silicon anode-based lithium-ion batteries: role of designer electrolyte additives and polymeric binders. ChemSusChem 12, 2515-2539 (2019).

15. Judez, X. et al. Opportunities for rechargeable solid-state batteries based on Liintercalation cathodes. Joule 2, 2208-2224 (2018).

16. Wen, C. J. \& Huggins, R. A. Chemical diffusion in intermediate phases in the lithium-silicon system. J. Solid State Chem. 37, 271-278 (1981).

17. Wu, J., Cao, Y., Zhao, H., Mao, J. \& Guo, Z. The critical role of carbon in marrying silicon and graphite anodes for high-energy lithium-ion batteries. Carbon Energy 1, 57-76 (2019)

18. Anothumakkool, B. et al. Electropolymerization triggered in situ surface modification of electrode interphases: alleviating first-cycle lithium loss in silicon anode lithium-ion batteries. ACS Sustain. Chem. Eng. 8, 12788-12798 (2020).

19. Müller, J. et al. Engineering si-on-graphite high-capacity anodes for Li-ion battery applications fabricated by fluidized bed process. Chem. Eng. J. 407, 126603 (2020)

20. Hamzelui, N., Eshetu, G. G. \& Figgemeier, E. Customizing active materials and polymeric binders: stern requirements to realize silicon-graphite anode based lithium-ion batteries. J. Energy Storage 35, 102098 (2021).

21. Dühnen, S. et al. Towards green battery cells: perspective on materials and technologies. Small Methods 4, 2000039 (2020).

22. Li, X., Zhang, M., Yuan, S. \& Lu, C. Research progress of silicon/carbon anode materials for lithium-ion batteries: structure design and synthesis method. ChemElectroChem 7, 4289-4302 (2020).

23. Pan, K., Zou, F., Canova, M., Zhu, Y. \& Kim, J.-H. Systematic electrochemica characterizations of $\mathrm{Si}$ and $\mathrm{SiO}$ anodes for high-capacity Li-ion batteries. $J$. Power Sources 413, 20-28 (2019).

24. Choi, J. W. \& Aurbach, D. Promise and reality of post-lithium-ion batteries with high energy densities. Nat. Rev. Mater. 1, 16013 (2016).

25. Liu, Z. et al. Silicon oxides: a promising family of anode materials for lithium ion batteries. Chem. Soc. Rev. 48, 285-309 (2019).

26. Kim, M. K., Jang, B. Y., Lee, J. S., Kim, J. S. \& Nahm, S. Microstructures and electrochemical performances of nano-sized $\mathrm{SiO}_{x}(1.18 \leq x \leq 1.83)$ as an anode material for a lithium(Li)-ion battery. J. Power Sources 244, 115-121 (2013).

27. Ulvestad, A., Mæhlen, J. P. \& Kirkengen, M. Silicon nitride as anode material for Li-ion batteries: understanding the $\mathrm{SiN}_{x}$ conversion reaction. J. Power Sources 399, 414-421 (2018).

28. Ulvestad, A. et al. Substoichiometric silicon nitride-an anode material for Liion batteries promising high stability and high capacity. Sci. Rep. 8, 8634 (2018).

29. de Guzman, R. C., Yang, J., Ming-Cheng Cheng, M., Salley, S. O. \& Ng, K. Y. $\mathrm{S}$. High capacity silicon nitride-based composite anodes for lithium ion batteries. J. Mater. Chem. A 2, 14577-14584 (2014).

30. Chae, S. et al. Gas phase synthesis of amorphous silicon nitride nanoparticles for high-energy LIBs. Energy Environ. Sci. 13, 1212-1221 (2020).

31. Winn, D. A., Shemilt, J. M. \& Steele, B. C. H. Titanium disulphide: a solid solution electrode for sodium and lithium. Mater. Res. Bull. 11, 559-566 (1976).

32. Zhang, $\mathrm{H}$. et al. Electrolyte additives for lithium metal anodes and rechargeable lithium metal batteries: progress and perspectives. Angew. Chem. Int. Ed. 57, 15002-15027 (2018)

33. Mizushima, K., Jones, P. C., Wiseman, P. J. \& Goodenough, J. B. $\mathrm{Li}_{x} \mathrm{CoO}_{2}(0<$ $\mathrm{x}<1$ ): a new cathode material for batteries of high energy density. Mater. Res. Bull. 15, 783-789 (1980).

34. Thackeray, M. M., David, W. I. F., Bruce, P. G. \& Goodenough, J. B. Lithium insertion into manganese spinels. Mater. Res. Bull. 18, 461-472 (1983).

35. Padhi, A. K., Nanjundaswamy, K. S. \& Goodenough, J. B. Phospho-olivines as positive-electrode materials for rechargeable lithium batteries. J. Electrochem. Soc. 144, 1188-1194 (1997). 
36. Manthiram, A., Knight, J. C., Myung, S.-T., Oh, S.-M. \& Sun, Y.-K. Nickel-rich and lithium-rich layered oxide cathodes: progress and perspectives. $A d v$. Energy Mater. 6, 1501010 (2016).

37. Li, W., Song, B. \& Manthiram, A. High-voltage positive electrode materials for lithium-ion batteries. Chem. Soc. Rev. 46, 3006-3059 (2017).

38. Nayak, P. K. et al. Review on challenges and recent advances in the electrochemical performance of high capacity Li- and Mn-rich cathode materials for Li-ion batteries. Adv. Energy Mater. 8, 1702397 (2018).

39. Chakraborty, A. et al. Layered cathode materials for lithium-ion batteries: review of computational studies on $\mathrm{LiNi}_{1-x-y} \mathrm{Co}_{x} \mathrm{Mn}_{y} \mathrm{O}_{2}$ and $\mathrm{LiNi}_{1-x-y} \mathrm{Co}_{x} \mathrm{Al}_{y} \mathrm{O}_{2}$. Chem. Mater. 32, 915-952 (2020).

40. Kuang, Y., Chen, C., Kirsch, D. \& Hu, L. Thick electrode batteries: principles, opportunities, and challenges. Adv. Energy Mater. 9, 1901457 (2019).

41. Jin, Y., Zhu, B., Lu, Z., Liu, N. \& Zhu, J. Challenges and recent progress in the development of Si anodes for lithium-ion battery. Adv. Energy Mater. 7, 1700715 (2017).

42. Obrovac, M. N. \& Chevrier, V. L. Alloy negative electrodes for Li-ion batteries. Chem. Rev. 114, 11444-11502 (2014)

43. Quinn, J. B., Waldmann, T., Richter, K., Kasper, M. \& Wohlfahrt-Mehrens, M. Energy density of cylindrical Li-ion cells: a comparison of commercial 18650 to the 21700 cells. J. Electrochem. Soc. 165, A3284-A3291 (2018).

44. Willenberg, L. et al. The development of jelly roll deformation in 18650 lithium-ion batteries at low state of charge. J. Electrochem. Soc. 167, 120502 (2020).

45. Selis, L. A. \& Seminario, JorgeM. Dendrite formation in silicon anodes of lithium-ion batteries. RSC Adv. 8, 5255-5267 (2018).

46. $\mathrm{Li}, \mathrm{T}$. et al. Degradation mechanisms and mitigation strategies of nickel-rich NMC-based lithium-ion batteries. Electrochem. Energy Rev. 3, 43-80 (2020).

47. Lin, Z., Liu, T., Ai, X. \& Liang, C. Aligning academia and industry for unified battery performance metrics. Nat. Commun. 9, 5262-5262 (2018)

48. Cao, Y., Li, M., Lu, J., Liu, J. \& Amine, K. Bridging the academic and industrial metrics for next-generation practical batteries. Nat. Nanotechnol. 14, 200-207 (2019).

49. Li, H. Practical evaluation of Li-ion batteries. Joule 3, 911-914 (2019).

50. Zhu, B. et al. Scalable production of Si nanoparticles directly from low grade sources for lithium-ion battery anode. Nano Lett. 15, 5750-5754 (2015).

51. Zhao, J. et al. Metallurgically lithiated siox anode with high capacity and ambient air compatibility. Proc. Natl Acad. Sci. USA 113, 7408-7413 (2016).

52. Meister, P. et al. Best practice: performance and cost evaluation of lithium ion battery active materials with special emphasis on energy efficiency. Chem. Mater. 28, 7203-7217 (2016).

53. Eshetu, G. G. et al. Electrolytes and interphases in sodium-based rechargeable batteries: recent advances and perspectives. Adv. Energy Mater. 10, 2000093 (2020).

54. Aupperle, F. et al. The role of electrolyte additives on the interfacial chemistry and thermal reactivity of si-anode-based li-ion battery. ACS Appl. Energy Mater. 2, 6513-6527 (2019).

55. Eshetu, G. G. et al. LiFSI vs. $\mathrm{LiPF}_{6}$ electrolytes in contact with lithiated graphite: comparing thermal stabilities and identification of specific SEIreinforcing additives. Electrochim. Acta 102, 133-141 (2013).

56. Tasaki, K. et al. Solubility of lithium salts formed on the lithium-ion battery negative electrode surface in organic solvents. J. Electrochem. Soc. 156, A1019-A1027 (2009)

57. Hu, Y.-S. et al. Superior storage performance of a $\mathrm{Si@SiO} x / \mathrm{C}$ nanocomposite as anode material for lithium-ion batteries. Angew. Chem. Int. Ed. 47, 1645-1649 (2008).

58. Schiele, A. et al. The critical role of fluoroethylene carbonate in the gassing of silicon anodes for lithium-ion batteries. ACS Energy Lett. 2, 2228-2233 (2017).

59. Kim, K. et al. Understanding the thermal instability of fluoroethylene carbonate in $\mathrm{LiPF}_{6}$-based electrolytes for lithium ion batteries. Electrochim. Acta 225, 358-368 (2017).

60. $\mathrm{Hu}, \mathrm{Z}$. et al. Trifluoropropylene carbonate-driven interface regulation enabling greatly enhanced lithium storage durability of silicon-based anodes. Adv. Funct. Mater. 29, 1906548 (2019).

61. Dong, $\mathrm{P}$. et al. Stabilizing interface layer of $\mathrm{LiNi}_{0.5} \mathrm{Co}_{0.2} \mathrm{Mn}_{0.3} \mathrm{O}_{2}$ cathode materials under high voltage using $p$-toluenesulfonyl isocyanate as film forming additive. J. Power Sources 344, 111-118 (2017).

62. Krause, L. J., Chevrier, V. L., Jensen, L. D. \& Brandt, T. The effect of carbon dioxide on the cycle life and electrolyte stability of Li-ion full cells containing silicon alloy. J. Electrochem. Soc. 164, A2527-A2533 (2017).

63. Plichta, E. An improved $\mathrm{Li} / \mathrm{Li}_{x} \mathrm{CoO}_{2}$ rechargeable cell. J. Electrochem. Soc. 136, 1865-1869 (1989).

64. Schwenke, K. U., Solchenbach, S., Demeaux, J., Lucht, B. L. \& Gasteiger, H. A. The impact of $\mathrm{CO}_{2}$ evolved from VC and FEC during formation of graphite anodes in lithium-ion batteries. J. Electrochem. Soc. 166, A2035-A2047 (2019).

65. Nölle, R., Schmiegel, J.-P., Winter, M. \& Placke, T. Tailoring electrolyte additives with synergistic functional moieties for silicon negative electrode- based lithium ion batteries: a case study on lactic acid O-carboxyanhydride. Chem. Mater. 32, 173-185 (2020).

66. Choi, N.-S., Yew, K. H., Kim, H., Kim, S.-S. \& Choi, W.-U. Surface layer formed on silicon thin-film electrode in lithium bis(oxalato)borate-based electrolyte. J. Power Sources 172, 404-409 (2007).

67. Han, J. G. et al. Unsymmetrical fluorinated malonatoborate as an amphoteric additive for high-energy-density lithium-ion batteries. Energy Environ. Sci. 11 1552-1562 (2018)

68. Philippe, B. et al. Improved performances of nanosilicon electrodes using the salt LiFSI: a photoelectron spectroscopy study. J. Am. Chem. Soc. 135, 9829-9842 (2013)

69. Trask, S. E. et al. Performance of full cells containing carbonate-based LiFSI electrolytes and silicon-graphite negative electrodes. J. Electrochem. Soc. 163, A345-A350 (2015).

70. Lindgren, F. et al. Sei formation and interfacial stability of a Si electrode in a LiTDI salt based electrolyte with FEC and VC additives for Li-ion batteries. ACS Appl. Mater. Interfaces 8, 15758-15766 (2016).

71. Chevrier, V. L. et al. Design and testing of prelithiated full cells with high silicon content. J. Electrochem. Soc. 165, A1129-A1136 (2018).

72. Liu, X. et al. Conformal prelithiation nanoshell on $\mathrm{LiCoO}_{2}$ enabling highenergy lithium-ion batteries. Nano Lett. 20, 4558-4565 (2020).

73. Kwon, T.-w, Choi, J. W. \& Coskun, A. The emerging era of supramolecular polymeric binders in silicon anodes. Chem. Soc. Rev. 47, 2145-2164 (2018).

74. Kwon, T.-w, Choi, J. W. \& Coskun, A. Prospect for supramolecular chemistry in high-energy-density rechargeable batteries. Joule 3, 662-682 (2019).

75. Qian, G. et al. Single-crystal nickel-rich layered-oxide battery cathode materials: synthesis, electrochemistry, and intra-granular fracture. Energy Storage Mater. 27, 140-149 (2020).

76. Yim, C.-h, Niketic, S., Salem, N., Naboka, O. \& Abu-Lebdeh, Y. Towards improving the practical energy density of Li-ion batteries: optimization and evaluation of silicon: graphite composites in full cells. J. Electrochem. Soc. 164 A6294-A6302 (2017).

77. Andre, D., Hain, H., Lamp, P., Maglia, F. \& Stiaszny, B. Future high-energy density anode materials from an automotive application perspective. J. Mater. Chem. A 5, 17174-17198 (2017).

78. Betz, J. et al. Theoretical versus practical energy: a plea for more transparency in the energy calculation of different rechargeable battery systems. Adv. Energy Mater. 9, 1-18 (2019).

79. Freunberger, S. A. True performance metrics in beyond-intercalation batteries Nat. Energy 2, 1-4 (2017)

80. Chae, C., Noh, H.-J., Lee, J. K., Scrosati, B. \& Sun, Y.-K. A high-energy Li-ion battery using a silicon-based anode and a nano-structured layered composite cathode. Adv. Funct. Mater. 24, 3036-3042 (2014).

81. Lee, J.-I., Lee, E.-H., Park, J.-H., Park, S. \& Lee, S.-Y. Ultrahigh-energy-density lithium-ion batteries based on a high-capacity anode and a high-voltage cathode with an electroconductive nanoparticle shell. Adv. Energy Mater. 4, 1301542 (2014).

82. Mazouzi, D. et al. Very high surface capacity observed using Si negative electrodes embedded in copper foam as 3D current collectors. Adv. Energy Mater. 4, 1301718 (2014)

83. Kim, J.-M. et al. All-nanomat lithium-ion batteries: a new cell architecture platform for ultrahigh energy density and mechanical flexibility. Adv. Energy Mater. 7, 1701099 (2017).

84. Liu, T. et al. Trifunctional electrode additive for high active material content and volumetric lithium-ion electrode densities. Adv. Energy Mater. 9, 1803390 (2019).

85. Zhang, L. et al. A yolk-shell structured silicon anode with superior conductivity and high tap density for full lithium-ion batteries. Angew. Chem. Int. Ed. 58, 8824-8828 (2019).

86. Li, P., Hwang, J.-Y. \& Sun, Y.-K. Nano/microstructured silicon-graphite composite anode for high-energy-density Li-ion battery. ACS Nano 13, 2624-2633 (2019).

87. Obrovac, M. N., Christensen, L., Le, D. B. \& Dahn, J. R. Alloy design for lithium-ion battery anodes. J. Electrochem. Soc. 154, A849-A849 (2007).

88. Chae, S., Kim, N., Ma, J., Cho, J. \& Ko, M. One-to-one comparison of graphite-blended negative electrodes using silicon nanolayer-embedded graphite versus commercial benchmarking materials for high-energy lithiumion batteries. Adv. Energy Mater. 7, 1700071 (2017).

89. Huang, Q. et al. Supremely elastic gel polymer electrolyte enables a reliable electrode structure for silicon-based anodes. Nat. Commun. 10, 5586 (2019).

90. Jia, H. et al. High-performance silicon anodes enabled by nonflammable localized high-concentration electrolytes. Adv. Energy Mater. 9, 1900784 (2019).

91. Jia, H. et al. Hierarchical porous silicon structures with extraordinary mechanical strength as high-performance lithium-ion battery anodes. Nat. Commun. 11, 1474 (2020)

92. Liu, N., Huo, K., McDowell, M. T., Zhao, J. \& Cui, Y. Rice husks as a sustainable source of nanostructured silicon for high performance Li-ion battery anodes. Sci. Rep. 3, 1919 (2013). 
93. Manthiram, A. A reflection on lithium-ion battery cathode chemistry. Nat. Commun. 11, 1550 (2020).

94. Iii, D. L. W., Li, J. \& Daniel, C. Prospects for reducing the processing cost of lithium ion batteries. J. Power Sources 275, 234-242 (2015).

95. An, S. J., Li, J., Du, Z., Daniel, C. \& Wood, D. L. Fast formation cycling for lithium ion batteries. J. Power Sources 342, 846-852 (2017).

96. Wu, H. \& Cui, Y. Designing nanostructured $\mathrm{Si}$ anodes for high energy lithium ion batteries. Nano Today 7, 414-429 (2012).

97. Liu, N. et al. A pomegranate-inspired nanoscale design for large-volumechange lithium battery anodes. Nat. Nanotechnol. 9, 187-192 (2014).

98. Li, X. et al. Mesoporous silicon sponge as an anti-pulverization structure for high-performance lithium-ion battery anodes. Nat. Commun. 5, 4105 (2014).

99. Chen, X., Li, H., Yan, Z., Cheng, F. \& Chen, J. Structure design and mechanism analysis of silicon anode for lithium-ion batteries. Sci. China Mater. 62, 1515 (2019).

100. Zhao, X. \& Lehto, V. P. Challenges and prospects of nanosized silicon anodes in lithium-ion batteries. Nanotechnology 32, 042002 (2021).

\section{Acknowledgements}

H.Z. acknowledges the support of the Fundamental Research Funds for the Central Universities (2020kfyXJJS095). H.A. acknowledges the support of the Hong Kong Quantum AI Lab (HKQAI). X.J. thanks the Basque Government for PhD funding. E.F. would like to thank the German Ministry of Research and Education (BMBF) for funding (Hi End, 03XP0084B). S.P. acknowledges the basic funding of the Helmholtz Association. G.G.E. and E.F. acknowledge the funding received from the European Commission via the H2020 IMAGE project (Grant Agreement Number: 769929-IMAGE-H2020-GV2016-2017/H2020-GV-2017).

\section{Author contributions}

G.G.E. instigated, G.G.E. and H.Z. conceived the work and wrote the initial draft. G.G.E. and H.Z. proposed, curated and prepared all the authors' custom figures, and X.J.

collected the physicochemical data of various electrode and electrolyte materials and estimated the energy densities. H.A. and S.P. deeply revised the manuscript draft. S.P., E.F. and M.A. supervised the work. All authors participated in the discussion and writing of the manuscript.

\section{Competing interests}

The authors declare no competing interests.

\section{Additional information}

Supplementary information The online version contains supplementary material available at https://doi.org/10.1038/s41467-021-25334-8.

Correspondence and requests for materials should be addressed to Stefano Passerini or Egbert Figgemeier.

Reprints and permission information is available at http://www.nature.com/reprints

Publisher's note Springer Nature remains neutral with regard to jurisdictional claims in published maps and institutional affiliations.

cc (i) Open Access This article is licensed under a Creative Commons Attribution 4.0 International License, which permits use, sharing, adaptation, distribution and reproduction in any medium or format, as long as you give appropriate credit to the original author(s) and the source, provide a link to the Creative Commons license, and indicate if changes were made. The images or other third party material in this article are included in the article's Creative Commons license, unless indicated otherwise in a credit line to the material. If material is not included in the article's Creative Commons license and your intended use is not permitted by statutory regulation or exceeds the permitted use, you will need to obtain permission directly from the copyright holder. To view a copy of this license, visit http://creativecommons.org/ licenses/by/4.0/

(C) The Author(s) 2021 